\title{
Residual Cochlear Function in Adults and Children Receiving Cochlear Implants: Correlations with Speech Perception Outcomes
}

\author{
T.E. Fontenot ${ }^{1}$, C.K. Giardina ${ }^{1,2}$, M.T. Dillon ${ }^{1}$, M.A. Rooth ${ }^{1}$, H.F. Teagle ${ }^{1}$, L.R. Park ${ }^{1}$, K.D. \\ Brown $^{1}$, O.F. Adunka ${ }^{3}$, C.A. Buchman ${ }^{4}$, H.C. Pillsbury ${ }^{1}$, and D.C. Fitzpatrick ${ }^{1,{ }^{*}}$ \\ ${ }^{1}$ University of North Carolina at Chapel Hill, Department of Otolaryngology, Chapel Hill, North \\ Carolina, 27258, \\ ${ }^{2}$ University of North Carolina School of Medicine, Chapel Hill, North Carolina, 27258, \\ ${ }^{3}$ The Ohio State University, Department of Otolaryngology, Columbus, Ohio, 43212, \\ ${ }^{4}$ Washington University in St. Louis, Department of Otolaryngology, St. Louis, MO, 63110
}

\begin{abstract}
Objectives-Variability in speech perception outcomes with cochlear implants (CI) remains largely unexplained. Recently, electrocochleography, or measurements of cochlear potentials in response to sound, has been used to assess residual cochlear function at the time of implantation. Our objective was to characterize the potentials recorded pre-implantation in subjects of all ages, and evaluate the relationship between the responses, including a subjective estimate of neural activity, and speech perception outcomes.
\end{abstract}

Design-ECochG was recorded in a prospective cohort of 284 candidates for CI at University of North Carolina (ages 10 months to 88 years). A measurement of residual cochlear function called the 'total response' (TR), which is the sum of magnitudes of spectral components in the response to tones of different stimulus frequencies, was obtained for each subject. The TR was then related to results on age-appropriate monosyllabic word score tests presented in quiet. In addition to the TR, the ECochG results were also assessed for neural activity in the forms of the compound action potential and auditory nerve neurophonic.

Results-The TR magnitude ranged from a barely detectable response of about $0.02 \mu \mathrm{V}$ to more than $100 \mu \mathrm{V}$. In adults (18-79 years old), the TR accounted for $46 \%$ of variability in speech perception outcome by linear regression $\left(r^{2}=0.46, p<0.001\right)$. In children between 6 and 17 years old, the variability accounted for was $36 \%$ ( $\mathrm{p}<0.001$ ). In younger children the TR accounted for less of the variability, $15 \%$ ( $\mathrm{p}=0.012$ ). Subjects over 80 years old tended to perform worse for a given TR than younger adults at the six month testing interval. The subjectively assessed neural

*Corresponding Author: Douglas Fitzpatrick PhD, 170 Manning Dr. CB\#7070, Chapel Hill, NC 27599-7070, Phone: (919) 966-3254,dcf@med.unc.edu.

Conflicts of Interest and Source of Funding

Dr. Fitzpatrick, Dr. Adunka, Dr. Buchman, Dr. Teagle, Dr. Pillsbury and Dr. Brown have consulting arrangements and research projects with MED-EL, Cochlear Corp and Advanced Bionics. This project was funded by NIH through NIDCD (5T32DC005360-12 and 1-F30-DC-015168-01A1) and by a research contract with MED-EL Corporation. 
activity did not increase the information compared to the TR alone, which is primarily composed of the cochlear microphonic $(\mathrm{CM})$ produced by hair cells.

Conclusion-The status of the auditory periphery, particularly of hair cells rather than neural activity, accounts for a large fraction of variability in speech perception outcomes in adults and older children. In younger children the relationship is weaker, and the elderly differ from other adults. This simple measurement can be applied with high throughput so that peripheral status can be assessed to help manage patient expectations, create individually-tailored treatment plans, and identify subjects performing below expectations based on residual cochlear function.

\section{INTRODUCTION}

Variability in speech perception outcomes with cochlear implants (CIs) is largely unexplained, making it difficult to accurately manage expectations, identify cases needing early additional rehabilitation, or determine if the device is working optimally for each patient. In adults, the main biographical factor typically seen to have a relationship with speech perception is duration of severe or profound hearing loss (e.g., Blamey et al. 1996; Blamey et al. 2013; Holden et al. 2013; Rubinstein et al. 1999). However, because of the increasing use of hearing aids this duration is declining in the CI population, making it less of a predictive factor (Holden et al. 2016; Lazard et al. 2012). Other significant factors are age (Holden et al. 2013) and surgical factors including number of active electrodes, their scalar placement, depth of insertion, and distance from the modiolus (Blamey et al. 2013; Finley et al. 2008; Holden et al. 2013; Lazard et al. 2012). Cognitive factors including brain reorganization subsequent to reduced or absent input are also involved (Anderson et al. 2016; Lee et al. 2007; Moore et al. 2009; Strelnikov et al. 2010). In children, age at implantation is a critical factor, with the earlier the implantation the better in cases of congenital hearing loss (Niparko et al. 2010). General developmental progress, as well as educational, habilitative, and parental environments contribute additional variables, particularly in the youngest children who meet criteria for implantation prior to the acquisition of language (Baumgartner et al. 2002; Blamey et al. 2001; Boons et al. 2012; Dunn et al. 2014). In most studies, the various factors identified, either in univariate or multivariate analysis, account for only a limited amount of variance in speech perception outcomes using the implant alone in quiet. For instance, a recent multicenter study with 2251 subjects included fifteen pre- and post-surgical factors in a multivariate regression. Using nine variables, the authors were only able to account for $22 \%$ of the variance in monosyllabic word scores (Lazard et al. 2012).

A factor that seems like it should affect outcomes is the prevalence of neural elements in the cochlea available for electrical stimulation. However, post-mortem analysis of surviving spiral ganglion cells and dendrites generally have not shown significant correlations with speech perception outcomes (Blamey 1997; Khan et al. 2005; Nadol et al. 2006), although two recent studies (Kamakura et al. 2016; Seyyedi et al. 2014) have shown significant relationships between ganglion cell density and speech perception outcomes in small samples ( $\mathrm{n}=6$ and 16 , respectively). A promising approach to directly measure the neural substrate is the electrically evoked compound action potential (ECAP). However, to date this measurement has not shown a significant relationship to speech perception outcomes 
(reviewed by van Eijl et al. 2017). This may be due to the small dynamic range (Cohen 2009), similar to the dynamic range limitation seen with electrical stimulation in auditory nerve fibers (Kiang et al. 1972), which limits the ability to discriminate among subjects. Recently, ECAP techniques that exploit growth functions and refractoriness of the auditory nerve are showing correlation with neural survival in animal studies, and may lead to an advance in this area for CI subjects (Kang et al. 2010; Kim et al. 2010; Ramekers et al. 2014; Strahl et al. 2016; Zhou et al. 2015; Zhou et al. 2016).

Another approach is to use electrocochleography (ECochG), or measurements of electrical signals produced by the cochlea in response to sounds, to characterize the functional status of the cochlea in each CI subject at the time of implantation. With monosyllabic word recognition in quiet at six months as the outcomes measure, the cochlear response magnitude using ECochG, taken intraoperatively at the time of implantation, was been able to account for $40-50 \%$ of the variability in a speech perception test performance in adults (Fitzpatrick et al. 2014; McClellan et al. 2014). Similarly, in a group of children >3 years old at time of implantation and from whom open set speech perception testing data in quiet was obtained within 16 months after implantation, $32 \%$ of the variability in word score outcomes was accounted for by cochlear response magnitude (Formeister et al. 2015). Thus, the functional status of the periphery appears to play a larger role in speech perception outcomes with CIs than previously reported.

The ECochG response is complex, with several distinct components arising from different combinations of hair cell and neural generators. These components are the compound action potential (CAP), seen as a transient deflection that represents synchronized neural activity to the onset of the stimulus. The CAP is present in about $50 \%$ of CI subjects, and when present can have a highly varied morphology making measurement difficult in some cases (Scott et al. 2016). The ongoing, alternating part of the response to low frequency tones is a mixture of both hair cell and neural activity, assuming neural activity is present in a given case. The hair cell contribution is the cochlear microphonic (CM) produced by mechanosensitive ion channels in the stereocilia of hair cells that open and close in response to displacement of the basilar membrane (Dallos 1973). The neural component is the auditory nerve neurophonic (ANN), which is produced by phase-locked responses of auditory nerve fibers (Forgues et al. 2014; He et al. 2012; Henry 1995; Lichtenhan et al. 2014; Snyder et al. 1984; E.

Verschooten et al. 2014; E. Verschooten et al. 2015). Although there is variation by species, in general the phase-locking weakens above about $1000 \mathrm{~Hz}$, and becomes negligible above 2-3 kHz (Weiss et al. 1988). Most evidence supports a similar range for humans (Joris et al. 2013). Thus, to frequencies above the phase-locking range the ongoing response is purely $\mathrm{CM}$, while to low frequencies it is CM plus the ANN in cases with phase-locked neural activity. An additional component is a constant shift from base-line shift during the tone stimulus, called the summating potential (SP). The SP is most evident to high frequencies, and is derived from a mixture of hair cell and neural sources (Dallos et al. 1972; Davis et al. 1958; Durrant et al. 1998; Forgues et al. 2014; Sellick et al. 2003; van Emst et al. 1995; Zheng et al. 1997).

In this study we present the most recent analysis of ECochG data and speech perception outcomes. Compared to previous studies, we extend the age range to the youngest CI 
recipients, implanted at $<3$ years old, and to the elderly ( $>80$ years). Young children make up one of the largest groups of the implant population, but require several years to reach the age where speech perception can be reliably tested. Older subjects are being increasing implanted, in part to help decrease social isolation associated with hearing loss and aging. In addition, in previous studies the overall magnitude of the ongoing response, summed across frequencies, was the measurement that showed a correlation with speech perception outcomes (Fitzpatrick et al. 2014; Formeister et al. 2015; McClellan et al. 2014). Since the measurement was overall magnitude, it did not discriminate the CM from the ANN. Here, we will test the hypothesis that additional information about speech perception outcomes can be obtained from knowledge of the neural contribution to the ECochG responses across subjects.

\section{MATERIAL AND METHODS}

\section{Subjects}

This prospective study was carried out with the approval of the institutional review board at the University of North Carolina at Chapel Hill. Informed consent was obtained from all adult participants. Parental consent was obtained for all pediatric subjects and patient assent was obtained from children between 7-18 years. Inclusion criteria for ECochG were that potential subjects were scheduled to receive a CI after the medical and audiological evaluation had established candidacy. Potential candidates were excluded from the study if they were not fluent in English, were undergoing revision surgery, or presented with severe inner ear malformations. The subject pool therefore consisted of the typical mix of subjects of all ages seen at a large implant center.

\section{Operative set up}

The recordings were performed intraoperatively from the round window (RW) of human CI subjects after exposure but prior to insertion of the implant array. Surface electrodes (Neuroline 720, Ambu Inc, Ballerup, Denmark) on the contralateral mastoid and forehead were the reference and common electrodes, respectively. The recording electrode was a monopolar stainless steel facial nerve monitor probe (Neurosign 3602-00-TE, Magstim Co., Wales, UK). Using a facial recess surgical approach the bony overhang of the RW recess was removed and the recording electrode placed in the RW niche. The RW was always closed for the recording session and prior to any cochleostomy. Impedance levels on all electrodes were less than $16 \mathrm{kOhm}$ prior to recording.

The stimulation and recording were controlled by a Biologic Navigator Pro (Natus Medical Inc., San Carlos, CA). Sound delivery was through an Etymotic speaker (ER-3b) connected by a sound tube to an in-ear foam insert. The ear was folded back and draped, so the earphone and sound tube were out of the sterile field. Tone burst stimuli at 6 different frequencies $(250,500,750,1000,2000$ and $4000 \mathrm{~Hz})$ were delivered at $90 \mathrm{~dB} \mathrm{nHL}(95-114$ $\mathrm{dB}$ peakSPL). Stimulation levels were calibrated to peakSPL using a $1 / 4 \mathrm{inch}$ microphone and measuring amplifier (Bruel \& Kjaer, Naerum, Denmark). Rise/fall times were one cycle or 1 $\mathrm{ms}$, whichever was longer, shaped by a Blackman window. All stimuli were presented in alternating condensation and rarefaction phases, with up to 250 repetitions to each phase 
(fewer repetitions were used if the response was large). Recordings were 512 points, and epochs were $32 \mathrm{~ms}(250-2000 \mathrm{~Hz}$ tone frequencies) or $10.66 \mathrm{~ms}(4000 \mathrm{~Hz})$. Stimulation rate was $17.3 / \mathrm{s}$ (250-2000 Hz tone frequencies) or 29.3/s (4000 Hz). The high-pass filter setting was $10 \mathrm{~Hz}$, and low-pass settings were $5000 \mathrm{~Hz}(250-1000 \mathrm{~Hz}$ tone frequencies), 10,000 Hz $(2000 \mathrm{~Hz})$ or $15,000 \mathrm{~Hz}(4000 \mathrm{~Hz})$. Recording gain was 50,000x. Artifact rejection was set at $47 \mu \mathrm{V}$ for most cases, higher values were used as necessary if the signal was large. A threshold series was obtained at one stimulus frequency in most subjects, usually $500 \mathrm{~Hz}$ unless another frequency had a markedly better response. Along with a level series of clicks taken in some subjects (not reported here) the battery of tests takes 5-10 minutes.

\section{Signal Analysis}

Recorded responses to the acoustic stimuli were processed using custom MATLAB (The Mathworks, Natick, MA,USA) software to plot time waveforms (an example is shown in Fig. 1A) and spectra (Fig. 1B). In the time waveform a prominent CAP is evident. The spectrum was determined from the ongoing response (colored box), which included several cycles of the stimulus frequency but excluded the CAP. In the spectrum, peaks were considered significant if they exceeded the noise floor by more than three standard deviations (i.e., above the filled circles in Fig. 1B), as measured from three bins on either side of the peaks. The TR is the sum of the significant peaks in each spectrum to the first three harmonics to each of the six stimulus frequencies (from 250 to $4000 \mathrm{~Hz}$ ), delivered at $90 \mathrm{~dB}$ nHL. For the examples in Fig. 1, the three peaks at 500, 1000 and $1500 \mathrm{~Hz}$ were significant and had a summed magnitude of $1.14 \mathrm{uV}$. The sum of response peaks for each of the other stimulus frequencies ranged from $0.36-0.89 \mu \mathrm{v}$ for 250,750 and $1000 \mathrm{~Hz}$, and there were no significant peaks to for 2000 and $4000 \mathrm{~Hz}$. The sum of all the significant peaks to all frequencies was $2.53 \mu \mathrm{v}$, for a TR of $8.1 \mathrm{~dB}$ re $1 \mu \mathrm{v}$. The peaks in the spectrum (Fig. 1B) are to condensation and rarefaction phases, but to utilize information from both phases for the calculation of the TR, the peaks to the first and third harmonics were taken from the difference of the two phases, and the peak to the second harmonic from their sum (bin width $=62 \mathrm{~Hz}$ ). Typically, the minimum detectable signal was approximately $0.02 \mu \mathrm{V}$ after 500 repetitions (250 presentations of each phase).

As mentioned the TR does not distinguish between hair cell and neural contributions. Here, we make an estimate of neural activity, to test the hypothesis that those with better neural activity will have better speech perception outcomes compared to the TR alone. We recently reported on a subjective metric for assessing neural activity in CI subjects, which we termed the "nerve score" (W. J. Riggs et al. 2017). The metric is based on observation of the presence and prominence of the CAP and ANN. As mentioned, the CAP is relatively easily observed when present, even when small, but can be difficult to measure, even when large, in part because of the influence of other sources such as the SP. Thus, the rating of the CAP can be 0 (no CAP), 1 (present but not prominent) or 2 (present and prominent, as in Fig. 1A). The neural contribution to the TR is from the ANN, which is difficult to isolate and separately measure (T.E. Fontenot et al. 2017; Lichtenhan et al. 2013; Lichtenhan et al. 2014; W. J. Riggs et al. 2017; Snyder and Schreiner 1984; E. Verschooten and Joris 2014; E. Verschooten et al. 2015). Both the CM and ANN produce distortions, but these are distinctive due to the different biophysical sources of hair cell and neural potentials (T. E. 
Fontenot et al. 2017). The distortions from the $\mathrm{CM}$ will be due to saturation of channel openings and closings as intensity is raised, which can produce both odd and even harmonics due to asymmetry to the two directions of stereociliary motion. Saturation should produce a flattening of the peaks in the time waveform. In contrast, distortions from the ANN are due to the shapes of action potentials and their distributions across nerve fibers, particularly the half-wave rectification that results because spike rate cannot go below zero (Rose et al. 1967). These types of distortion are best observed in the 'average cycle' (Fig. 1C). This curve is the average to each stimulus cycle in the ongoing response in Fig. 1A (colored box). Distortions in the average cycle that are not a simple saturation of the peaks and troughs can be thus be related to neural activity. We have developed a model-based system from these biophysical principles to titrate amounts of CM and ANN needed to define shapes of the average cycles, and validated the model with animal data where the responses from each source can be separated pharmacologically (T. E. Fontenot et al. 2017). The model had high accuracy and is a promising approach, but as presently implemented it is not as sensitive as the visual appearance of the average cycle, where even a small distortion that is not saturation is readily apparent. Thus, like the CAP, the ANN was rated as a 0 (no or only saturating distortions), a 1 (clear but small non-saturating distortions) or a 2 (prominent non-saturating distortions, as in Fig. 1C). The nerve score is then the addition of the ratings for CAP and ANN, and can range from 0-4. Because the both the CAP and ANN had separate ratings of two, the nerve score for the case in Fig. 1 was a four, the maximum. The interested reader is referred to Riggs et al for examples of the full range of nerve scores.

The nerve scores were determined independently by three observers. There were no cases where a CAP or ANN differed by two points among observers. For cases where one observer differed by a point from the other two, the case was examined and the reason for the choice discussed and a consensus reached.

\section{Audiometry}

Pre-implant audiometric thresholds were collected by licensed audiologists via conventional methods, conditioned play audiometry (CPA), or visual reinforcement audiometry (VRA) depending on the subject's age and developmental abilities. For adults, the thresholds were determined for an audiometric frequency series of 250, 500, 1000, 2000, $4000 \mathrm{~Hz}$. For children, the preoperative audiometry stored was the pure tone average thresholds to 500, 1000 and $2000 \mathrm{~Hz}$. For frequencies where no response was obtained the value recorded was $120 \mathrm{~dB} \mathrm{HL}$, since the maximum output of the audiometer is $115 \mathrm{~dB}$, so 120 allows for a designation of no response. After surgery, the CI recipients were followed for CI programming, aural rehabilitation and speech perception assessment with age and developmentally appropriate speech perception tests presented in English. Cochlear implantaided speech perception testing was conducted in a soundproof booth with the subject seated 1 meter away from the sound source. Recorded materials were presented at $60 \mathrm{~dB}$ SPL.

The outcome measure is recognition of monosyllabic words in quiet. These tests are the commonly used to measure speech perception with the implant in both children and adults, because it is a relatively difficult test and separates the population to a greater degree than other tests with more context, such as with sentences (Gifford et al. 2008). Hearing in noise 
has long been known to be a particular challenge to implant users, and a battery including tests in noise is typically applied ("MSTB: The New Minimum Speech Test Battery. 2011"). In particular, subjects with residual hearing that is preserved through the CI surgery achieve benefits in noisy environments (Adunka et al. 2013; Gifford et al. 2013). However, most implantations are done in subjects that fit standard criteria of moderate and profound hearing loss, and hearing preservation is not a goal of the procedure. The use of ECochG in this study covers the broad mix of implant subjects, so results in quiet provide the highest discrimination of the range of abilities in these subjects (Gifford et al. 2008). In addition, the measurement of cochlear responses with ECochG are not equivalent to a measurement of hearing, because the responses are highly variable and can be large even in cases with profound hearing loss (Fitzpatrick et al. 2014).

Adult speech perception performance was measured using consonant-nucleus-consonant (CNC) word tests (Peterson et al. 1962). This test assesses the understanding of isolated words in quiet and eliminates context cues potentially provided in sentence tests (Gifford et al. 2008). The test is scored as a percent correct out of 50 words. The CNC word scores that were obtained at 6 months post-initial activation of the external audio processor was the outcome measure selected for the analysis.

For pediatric subjects, phonetically balanced kindergarten word test (PB-k) was the outcome measure (Haskins 1949). The test consists of phonetically balanced isolated monosyllabic words commonly known by normal-hearing kindergarten aged children. Therefore, to be tested with PB-k, the pediatric CI recipients must have reached an age appropriate for openset word speech perception testing (usually 4-5 years old) and have achieved sufficient progress on previous, less challenging tests of the Speech Recognition Index testing battery (Teagle et al. 2010; Wang et al. 2008). The test is administered in a soundproof booth with the listener facing the speaker at 0 degree azimuth using either monitored live voice (MLV) or recorded list condition at $60 \mathrm{~dB}$ SPL. Unlike adults, the timeline and trends in speech perception performance improvements of pediatric CI recipients are less defined and may continue beyond 5 years from initial activation (Ahmad et al. 2012). For the purposes of the analyses in this study, a pediatric subject's performance on the test was deemed stable when at least two PB-k scores in ipsilateral condition were within 10 percentage points of each other during consecutive testing sessions (typically $0.5-1$ year apart). The first stable PB-k score obtained under recorded condition after at least 9 months of $\mathrm{CI}$ use was selected as the outcome measure for this study.

\section{Statistical Analysis}

Statistical analysis was performed using MATLAB R2015b and IBM SPSS Statistics 24 software. Univariate linear regression was used to determine the correlation and regression coefficients for TR and aided speech perception outcomes. Subjects who were not able to complete speech perception testing and outliers from the main trends are included on the plots but were excluded from the regression analyses. The outliers were identified by a combination of criterion, using Cook's distance (obtained from MATLAB function fitlm) and from identification of points with the largest influence on the $\mathrm{r}^{2}$ (using MATLAB FileExchange function regoutliers, which implements the Thompson tau version of a t-test 
on the residuals of the regression, with residuals obtained using MATLAB function regstats). The process was done iteratively, if removal of the point with the largest influence increased the $\mathrm{r}^{2}$ significantly (at the 0.05 level) the point was checked to see if was also an outlier by Cook's distance $>3$ times the mean, and if so was considered an outlier and removed (i.e. two criteria were met). If removal of the point with the largest influence did not increase the $\mathrm{r}^{2}$ but the case with the largest Cook's distance was $>6$ times the mean (i.e., only 1 cirteria met but the other criteria very strong), the case was considered an outlier and removed. This process was repeated until no points fit the criteria for an outlier.

\section{RESULTS}

Table 1 shows summaries of demographic and audiological properties, and of the devices used, for the 84 adults with ECochG and CNC word scores outcomes used in the study. This cohort excludes those whose severe hearing loss began prelingually $(\mathrm{n}=10)$, who were lost to follow-up ( $n=37$ ), or who did not have scores over the interval studied $(n=35)$. The two groups are the main group of adults $<80$ years old $(n=73)$, and the elderly, who were 80 years and older $(n=11)$. Justification for separating these two age groups is based on multivariate regression results that will be provided below. In both groups, the most prevalent etiology leading to implantation was sensorineural hearing loss of unknown origin. The majority of devices were from MED-EL, with most of these of the standard type (31.5 $\mathrm{mm}$ length) and others of the Flex or medium category (24-28 mm length).

Table 2 shows summaries of demographics, audiological properties, and devices, for the 94 children with ECochG and PB-k word scores outcomes used in the study. The two age groups are divided into older and younger children, with the division into the older group occurring at an age at implantation of 6 years. The reason for separating younger from older children between ages 5 and 6 is based on a regression analysis of the word score data that will be described later. In the younger group, 9 were MLV, and for the remainder recorded voices were used. The 3 -tone $(0.5,1$ and $2 \mathrm{kHz})$ average behavioral thresholds were about 8 $\mathrm{dB}$ lower in the younger children compared to older children, and this difference approached significance (two-tailed Students t-test, $\mathrm{t}=-2.1, \mathrm{dF}=45.1, \mathrm{p}=0.0501$, passed KolmogorovSmirnov test of normality). The younger children also had a longer duration of CI use expected since the time required to reach an age appropriate for word score testing was longer. The average PB-k score was nearly the same between the two groups. In terms of etiology, children with ANSD were common in both age groups. For these children, which also includes those with cochlear nerve deficiency based on MRI, the designation of ANSD was defined by the presence of a $\mathrm{CM}$ but small or absent wave $\mathrm{V}$ in auditory brainstem responses (Buchman et al. 2006; Sininger 2008; Teagle et al. 2010). Characteristics of their ECochG, including distributions of nerve scores, have been described elsewhere (W. J. Riggs et al. 2017). Sensorineural hearing loss of unknown origin was common, and there were a variety of other etiologies documented. The mix of devices was different from adults, with most being the Cochlear Corporation Nucleus CI512 or Freedom CI24E device which both have modiolar-hugging electrode arrays. 


\section{Distribution of TR for different age groups and across frequencies}

A total of 284 subjects had preoperative ECochG recordings. The age range was 10 months to 88 years old. Almost all CI subjects $(275 / 284,97 \%)$ showed a significant response to acoustic stimuli at one or more frequencies. The TR spanned from the smallest detectable signal of just above $0.02 \mu \mathrm{V}$ to a maximum of $>100 \mu \mathrm{V}$ (range $>70 \mathrm{~dB}$ ). The variability of the TR was wide across all ages (Fig. 2A). The slope of the linear regression line was not significantly different from zero ( $\mathrm{p}=0.19)$. When compared in age groups (Fig. 2B), the younger children $(<6$ years old) had slightly smaller values overall but the effect of age group was not significant (One-way ANOVA, $\mathrm{df}=2,282, \mathrm{~F}=2.18, \mathrm{p}=0.12$ ). When broken down by stimulus frequency (Fig. 2C), most subjects showed significant responses to frequencies of $250-1000 \mathrm{~Hz}$, while smaller numbers showed responses to 2000 and $4000 \mathrm{~Hz}$ (Fig. 2D). When considered in terms of the contribution of each stimulus frequency to the TR, responses to $250 \mathrm{~Hz}$ and $500 \mathrm{~Hz}$ contributed the most, for both the first harmonic (H1, at the stimulus frequency, measured from the difference between the alternating phases of the stimulus) and second harmonics ( $\mathrm{H} 2$, at twice the stimulus frequency, measured from the sum). The $\mathrm{H} 1$ is dominated by the $\mathrm{CM}$, and when large, the $\mathrm{H} 2$ is dominated by the ANN (although the separation is not clean, for reasons described previously). Thus, even to low frequencies, which contribute the most to the response and where the ANN is largest, the CM still appeared to be the dominant component.

The ECochG distributions across frequencies were similar for the three age groups. In the following analysis, a 2-way ANOVA of the factors of stimulus frequency and age group were used separately for the $\mathrm{H} 1$ and $\mathrm{H} 2$. Both analyses showed significant effects of the stimulus frequency but not of age group, and a significant interaction between frequency and age group $\left(\mathrm{df}_{\text {frequency }}=5, \mathrm{df}_{\text {age }}=2, \mathrm{df}_{\text {interaction }}=10, \mathrm{df}_{\text {error }}=1626 ; \mathrm{F}_{\text {frequency }}=124\right.$ and 117 for $\mathrm{H} 1$ and $\mathrm{H} 2$, respectively, both $\mathrm{p}$ values $<0.001 ; \mathrm{F}_{\mathrm{age}}=0.01$ and 0.69 , respectively, both $\mathrm{p}$ values $>0.5, \mathrm{~F}_{\text {interaction }}=3.83$ and 3.5 , respectively, both $\mathrm{p}$ values $<0.001$. A possible reason for the interaction between frequency and age group in the case of the H1 is the higher proportion of the TR carried by high frequencies for the younger children, which is in turn due to the prevalence of auditory neuropathy spectrum disorder (ANSD) in this group (see Table 2). Cases with ANSD typically have a large TR to high frequencies (1000-4000) compared to non-ANSD subjects. The reason for the significant interaction between frequency and age group is the relatively large proportion of the TR provided by low frequency responses in the youngest children, but an explanation for this is not clear.

\section{Relationship between TR and speech perception outcomes in adults}

In most adults $<80$ years old, the correlation ( $\mathrm{r}$ ) between TR and $\mathrm{CNC}$ score, excluding outliers $(n=4)$ and those who did not reach word score testing $(n=2)$ was 0.675 , accounted for $46 \%$ of the variability (Fig. 3, line). The outliers all had large TRs but lay below the line of regression. Two subjects (X symbols) did not achieve open set speech perception by 6 months post-implantation, with no obvious reasons.

This pattern of results is similar to what has been reported previously (Fitzpatrick et al. 2014), although with a larger number of subjects, and after also removing more elderly subjects, as was not done previously but will be described further below. In Fig. 4A, we 
include a new factor in the analysis, the nerve score (see Methods). The data is the same as in Fig. 3, but with a binary distinction of nerve scores plotted. For cases with a large TR, above about $10 \mathrm{~dB}(3.1 \mu \mathrm{V}$, to right of both dashed lines), nerve scores $>2$ were generally obtained (30/32 cases), indicating the presence and often prominence of the CAP and/or the ANN. Only two cases with a nerve score less than 2 were identified in this group. Possibly of interest, both had relatively low speech perception performance, including one of the outliers (circled). The other three outliers, also in this large TR group, all had good nerve scores. For cases with low TRs, below about $0 \mathrm{~dB}$ (smaller than the left dashed line), there was never an indication of a response that was other than CM. Only in the narrow middle group, with TRs from -0.5 to $10 \mathrm{~dB}(0.5$ to $3.16 \mu \mathrm{V})$, was there a mixture of good and poor nerve scores. However, there was no systematic pattern; cases with a poor nerve score had speech perception scores both above and below the regression line, as did cases with good nerve scores.

To test the hypothesis that there was a relationship between nerve score and speech perception outcome, a stepwise regression was done using TR as one factor and nerve score as another. No significant increase in $\mathrm{r}^{2}$ by including the nerve score compared to TR alone was found (change in adjusted $\mathrm{r}^{2}=-0.01, \mathrm{df}=1,65, \mathrm{p}=0.77$ ). Even when the poor nerve outlier was included, under the idea that the relatively low word score would be related to its limited neural response, this also did not result in a significant change in $\mathrm{r}^{2}$ for the population $(\mathrm{p}=0.39)$.

As mentioned, in Fig. 3 adults 80 years and older were excluded, in contrast to the previous study. The reason for this is shown in Figs. 4B and C. In Fig. 4B, it can be seen that the CNC word score outcomes at six months for the elderly were generally lower than for the younger adults, although there was overlap (Fig. 4B). There was also one case of no word score in an 80 year old subject (not shown). A stepwise regression of TR and CNC of both groups showed an $\mathrm{r}^{2}$ of 0.28 when all subjects $(\mathrm{n}=77)$ were included, while the step of including the age group raised the adjusted $\mathrm{r}^{2}$ to 0.49 , and the increase was significant $(\mathrm{dfs}=1,74, \mathrm{~F}=32.6$, $\mathrm{p}<0.001)$. The correlation between the TR and word score in the elderly group was not significant by itself $(\mathrm{p}=0.24)$. For an additional analysis we did a series of linear regressions with age cohorts starting first from the youngest adults and then progressively adding older subjects in two year steps (Fig. 4C). The first group with a significant $\mathrm{r}^{2}$ was the 8 cases younger than 40 years old $\left(r^{2}=0.59, p=0.026\right)$. The $\mathrm{r}^{2}$ values when older subjects were sequentially included remained significant and fluctuated between 0.60 (ages $<56, \mathrm{n}=23$ ) to 0.45 for ages $<80(n=67)$, but then declined substantially when ages of 80 and older were included.

\section{Relationship between TR and speech perception outcomes in pediatric subjects}

In Table 2, children were separated between an older group and a younger group, with the division into the older group starting at age 6 at the time of implantation. The reason for this is empirical, and is shown in Fig. 5, where an incremental regression analysis was performed in pediatric CI recipients, similar to that in adults but starting with inclusion of the oldest children, and progressively adding children of younger ages. This analysis showed that there was sharp break in word score outcomes that could be accounted for by the TR in older 
children at about age 6 at the time of implantation. As with the adults, the subjects included in this regression analysis were a subset of all children in the study, excluding outliers and those who had not achieved speech perception outcomes at an age and duration of use where testing could have been performed (see Fig. 6).

For the older children, the relationship between TR and PB-k, excluding outliers $(n=2)$ and those that did not achieve word scores $(n=3)$, was similar to that found in adults $\left(r^{2}=0.38\right.$, Fig. 6A, compared to 0.46 in adults). In contrast, in the younger children the relationship between TR and speech perception outcomes was notably weaker $\left(\mathrm{r}^{2}=0.15\right)$ (Fig. 6B). Other differences in the younger group were a new class of outlier and a larger number of cases that did not achieve speech ability. The new outlier group (squares) was characterized by a low or absent TR coupled with good word score outcomes. This result implies that there was a relatively poor cochlear substrate to support responses to sound, but a reasonably good neural substrate available for electrical stimulation. Two of these (with PB-k scores using each ear near 90\%) were from a 1-year old subject with meningitis as the cause of deafness. Meningitis produces fibrosis of the cochlea, consistent with a low TR (i.e., poor hair cell activity), but a preserved auditory nerve available for stimulation. The other case had an absent ECochG but a PB-k score near 60\%. The cause of hearing loss in this subject was genetic mutations of connexin 26 and 30. This condition affects gap junction and maintenance of the endocochlear potential, and is also consistent with a low TR but good underlying neural substrate available for electrical stimulation.

There were a variety of backgrounds for the large number of young children $(n=13)$ who did not progress to open-set speech at the age where it would be expected (4-5 years old). There were two cases with cochlear nerve deficiency on MRI, seven with cognitive or behavioral issues that led them to being non-users of their implants, and four who had no obvious reasons for their poor performance.

The distributions of the nerve scores were similar between both groups of children and adults. Most children with TRs $>10 \mathrm{~dB}(3.16 \mu \mathrm{V}$, greater than right dotted lines in Figs. 7A and B) showed considerable neural activity in their ECochG (10/15 older children, 12/15 younger). while cases with small TRs consisted solely of CM, and thus had low nerve scores. For cases in the middle, there was a mixture of good and poor nerve scores, but with no obvious systematic trends. As with the adults, knowledge of the status of neural contribution did not significantly improve the correlations with word score outcomes compared to the TR alone (stepwise linear regressions, p's $>0.05$ ). A difference from adults was that several in the group with high TRs but poor nerve scores had speech perception scores above the regression lines. Another difference was that some cases with no word scores had TRs large enough for nerve scores to be determined (along the bottoms of the plots), and these were a mixture of good and poor nerve scores.

\section{EcochG Thresholds}

Thresholds to ECochG stimuli were measured to one stimulus frequency, usually but not always $500 \mathrm{~Hz}$, in most subjects (244/284 cases). Thresholds were determined as the lowest intensity with a significant response in the FFT located at the stimulus frequency. There was a significant relationship between the threshold and response magnitudes (sum of all 
significant peaks in the FFT) to $90 \mathrm{~dB} n \mathrm{~nL}$ at the same frequency (Fig. 8A). A linear fit to these points had an $\mathrm{r}^{2}$ of 0.57 ( $\mathrm{p}<0.001, \mathrm{n}=244$, dashed black line). The slope of this fit was less than 1, suggesting some saturation, so the data were also fit with a sigmoidal function, which produced an $\mathrm{r}^{2}$ of $0.59(\mathrm{p}<0.001)$. Since this was only marginally better than the linear fit the degree of saturation appears to be small.

Another use of the ECochG thresholds was for a comparison with audiometric thresholds (Fig. 8B). This information was available for individual frequencies only for adults, and of these, was only collected for those where word scores were also obtained. There were total of 84 adult subjects with audiometric data, a threshold from ECochG was taken in 74. In these subjects, there was a significant relationship between ECochG and audiometric thresholds $\left(\mathrm{r}^{2}=0.40, \mathrm{p}<0.001\right)$. Interestingly, many ECochG thresholds were lower than the behavioral (above the line of equality - dashed).

\section{DISCUSSION}

ECochG offers a sensitive and detailed view of the status of the auditory periphery across the age spectrum. The sum of spectral magnitudes of the ongoing response, or TR, accounted for a large fraction of the variability in speech perception outcomes $(46 \%)$ in nonelderly ( $<80$ years) adults, excluding outliers and those who did not reach an ability for word score testing. A similar result (36\% variability accounted for) was seen in older children (implanted at $>5$ years). In contrast, for children implanted five years and younger the relationship was much weaker (15\% variability accounted for). In these adults and both groups of children, exceptions to the general trends were seen, either as outliers with lower speech perception than expected from their large TR, or in the case of young children, higher speech perception scores than expected from their low TR. Failure to achieve word score testing was also seen more often in younger than in older children or adults, and these could be children with any level of residual cochlear function. Surprisingly, knowledge of neural activity in the form of a subjective nerve score based on the appearance of the CAP and ANN did not increase the information available from the TR alone. This result was seen in adults and both groups of children, and indicates that hair cell, rather than neural, activity in response to sound is the most important component for speech perception outcomes.

At the other extreme of age the elderly subjects tended to perform worse for a given TR than other adults at the same 6-month post-operative interval. They did not show a significant relationship between TR and word scores, but were separable as a group from other adults based on their influence on a multivariate regression and regressions computed sequentially with age.

\section{Why does the TR account for so much of the variability in speech perception outcomes in adults and older children?}

The proportions of the variability in speech perception outcomes measured in quiet that are accounted for by the TR are higher than for any other single measure or combination of measurements reported in the literature, which rarely exceeds about $25 \%$ (e.g., Blamey et al. 2013; Dowell et al. 2002; A. Geers et al. 2003; Holden et al. 2013). An important feature of the TR is that it varies over a greater than $70 \mathrm{~dB}$ range across subjects (Fig. 2). This wide 
dynamic range provides the ability to discriminate among subjects, which is a necessary but not sufficient reason for the success of the TR to account for the wide variation in outcomes. The next step must be to link the ECochG responses to a causal explanation about how the ECochG response leads to understanding speech perception outcomes. The ongoing part of the ECochG signal contains both the CM and ANN. The presence of the ANN can be detected by the shape of the ongoing waveform (T. E. Fontenot et al. 2017; W.J. Riggs et al. 2017), by spectral methods (Henry 1995; Lichtenhan et al. 2013; Lichtenhan et al. 2014), or by forward masking (Henry 1995; Snyder et al. 1985; E. Verschooten and Joris 2014; E Verschooten et al. 2013). No method is available to discretely quantify the amounts of ANN and CM, but animal studies where the ANN can be removed with neurotoxins show that the CM dominates for most frequency/intensity combinations (T.E. Fontenot et al. 2017; Forgues et al. 2014; He et al. 2012; Lichtenhan et al. 2013; E. Verschooten and Joris 2014). The results in Fig. 2D show that the H1, which is purely $\mathrm{CM}$ at high frequencies and (depending on the case) a mixture of CM and ANN at low frequencies, dominates the response. A model-based approach, described briefly in the Methods, also showed the CM to dominate even to low frequencies in the same group of CI subjects (T. E. Fontenot et al. 2017).

Still, it might be expected that the presence of nerve activity would provide additional information that correlates with speech perception outcomes, and thus improve the correlation with compared to the TR alone. However, this was not seen - instead all but a few cases with large TR also had good evidence of neural activity in the form of an ANN and/or CAP, while those with small TR had mainly or only CM. Only in the middle range was there a mixture of good and poor nerve scores, but the distributions were not systematically related to word scores. To help explain this result, which goes against our initial hypothesis, we note that neural activity is a requirement for behavior, but the effect of preoperative audiometric thresholds on postoperative speech perception outcomes is typically absent or small (Gifford et al. 2010; Holden et al. 2013; Holden et al. 2016; Lazard et al. 2012). In a previous study we found a correlation between preoperative audiometric thresholds and speech perception outcomes, contributing an $\mathrm{r}^{2}$ able to account for about $20 \%$ of the variation (McClellan et al. 2014). However, when added in a hierarchical regression, there was no significant increase in $\mathrm{r}^{2}$ compared to the TR alone, or between age and duration of moderate, unaided hearing loss, indicating the TR as a single predictor was robust and able to account for differences in other factors such as age or duration of deafness. The number of subjects in that case was 32 compared to 67 here, but the $\mathrm{r}^{2}$ for PTA alone is still 0.2 , and continues to have no additive effect when combined with the TR (data not shown since it has not changed from the previous report). Thus, by primarily measuring hair cell rather than neural activity, the TR is providing information related to outcomes that is not available in the audiogram or in the residual neural responses seen in ECochG. It therefore appears that the ANN is if anything a contamination of the ability to accurately measure the CM, which is the signal that provides the predictive power for outcomes. Fortunately the $\mathrm{CM}$ is the larger of the two, so the metric still works well, and in any case the ANN appears to correlate with the CM so the contaminating effect would be small (T. E. Fontenot et al. 2017). 
Why would functioning hair cells in response to sound predict the neural substrate available for electrical stimulation? Spiral ganglion cells unconnected to functioning hair cells are the basic substrate that lead to electrical hearing with the implant. So measurement of hair cell activity can only be an indirect proxy of neural survival, as an indication of the overall functional status of the cochlea. A connection between the surviving hair cells and disconnected neurons could be related to neurotrophins providing a functioning organ of Corti, even if hair cells are not connected to nerve fibers (Green et al. 2012; Suzuki et al. 2016). This type of explanation would not have been considered plausible until recently, because of the long-held view that hair cells are the most sensitive cochlear element to trauma such as from noise, and would therefore be absent prior to any loss of neural activity. However, recent animal studies have challenged the view that hair cells are the most sensitive element, pointing instead to the synapse between the IHC and nerve fibers as subject to excitotoxicity if excessively stimulated (Kujawa et al. 2009, 2015; Liberman et al. 2016; Lin et al. 2011). In this view, the degree of hearing loss in adults and older children leading to cochlear implantation could be a form of congenital or progressive synaptopathy, rather than strictly due to loss of functioning hair cells, although this occurs as well (Schuknecht et al. 2010). While the question of whether this 'hidden hearing loss' is present in humans is currently under active study, the results here support the view that functioning hair cells in humans can indicate a good neural substrate available for electrical stimulation, while lack of functioning hair cells indicates a cochlea with more neural loss as well.

The argument that the health of the cochlea, particularly in terms of surviving, functional neural elements, should be important for speech perception outcomes has been previously made (Pfingst et al. 2015). Studies based on advanced uses of ECAP including pulse-rate integration and forward masking, validated in animal studies, show promise of more directly measuring the functional neural substrate available for electrical stimulation (DeVries et al. 2016; Kang et al. 2010; Ramekers et al. 2014; Strahl et al. 2016; Zhou et al. 2015; Zhou and Pfingst 2016). Ultimately, both ECochG and ECAP methods may prove useful in characterizing the functional status of the periphery available for electrical stimulation.

Our cohort of adult subjects (Table 1) was primarily composed of those receiving MED-EL implants, which are designed as lateral wall electrodes intended to reduce basilar membrane trauma and translocations from scala tympani to scala vestibuli during insertion. Most of these had a length of $31.5 \mathrm{~mm}$, intended to reach to the cochlear apex, although some were 24 or $28 \mathrm{~mm}$ intended for hearing preservation. Previous studies have shown significant effects of translocation (Finley et al. 2008; Holden et al. 2013), insertion depth (O'Connell et al. 2016; O'Connell et al. 2017) and distance from the modiolus (Holden et al. 2013) on speech perception outcomes. Because such surgical factors are independent of residual function as measured by ECochG, they should in principle be an additional factor that when used in a multivariate analysis would increase the overall variability in speech perception outcomes accounted for compared to the TR alone.

\section{Why are the elderly different?}

We found a difference in the effect of TR on speech perception outcomes for adults over the age of 80 . The range of TRs was similar to other adults, but lower overall speech perception 
was seen both when these subjects were added sequentially to the regression analysis and when considered as a separate group in a multivariate regression. Previous studies have shown a decline (Friedland et al. 2010; Roberts et al. 2013) or delay (Dillon et al. 2013) in performance for subjects over 80 . These results and previous findings suggest central rather than peripheral factors are the most likely cause for the difference from other adults.

\section{Why does the TR account for less variability in word score outcomes in children younger than six years old?}

A number of factors could be related to the lower correlation between TR and speech perception scores between the young children and the older groups. First, most of the children implanted at $<6$ years old had limited or no experience with speech prior to onset of deafness, in contrast to the adults and most of the older children whose hearing loss was postlingual. Children implanted at $<6$ years old were also tested at a younger age overall (Table 2), and so were at a different developmental stage relative to language exposure and usage compared to the other groups (Benasich et al. 2014; Davidson et al. 2011; Dunn et al. 2014). Issues related to home, education and patient acceptance of the device also play an important role in the youngest children (A. Geers et al. 2003; A. E. Geers et al. 2011). Finally, central nervous system plasticity is likely to be greatest in the youngest children possibly leading to better outcomes in the face of impoverished inputs, and the majority of the youngest pediatric subjects generally receive long-term intensive therapy with their $\mathrm{CI}$ to take advantage of this plasticity (Dunn et al. 2014; Gervain 2015). The increased plasticity combined with training would be expected to help young children with a low TR to have a better outcome than expected, consistent with the lower slope observed (Fig. 6B, Table 2).

In addition to the issues listed above, another possible major factor is the different causes of deafness between those with congenital hearing loss compared to those who acquire such loss at an older age. Conditions which cause early and severe damage to hair cells or the supporting cells of the cochlea, such as mutations in connexin genes or meningitis, do not necessarily have an immediate effect on the function of the auditory nerve (Aminpour et al. 2005; Wingard et al. 2015). Thus, in children with congenital etiologies that affect hair cells, a small TR may not necessarily indicate a poor underlying neural substrate. Extreme examples of this condition were the outliers seen only in the young children with a low or absent TR but good word score outcomes (Fig. 5A). One of these cases (two ears) had meningitis and the other had mutations in genes for connexins 26 and 30, both of which should involve primarily hair cells and not spiral ganglion cells. The converse is true for conditions that are putatively specific to neural transmission rather than cochlear disorder, i.e., cases with ANSD. In these cases, the ECochG response from hair cells can be large but does not indicate the presence of healthy underlying neural substrate. Cases with cochlear nerve deficiency exemplify this type of condition. The ECochG results from the ANSD children has been described elsewhere, with the result that the large TR is due primarily to the presence of the CM to high frequencies, rather than the absence of neural responses to low frequencies (W. J. Riggs et al. 2017). This explanation is why most of the cases with high TR also have good nerve scores, with the neural activity largely limited to low frequencies but not otherwise different from children without ANSD (W. J. Riggs et al. 2017). Thus, the difference in the ECochG results between young children compared to 
older children and adults may be due in large part to the differences between congenital and progressive hearing loss.

\section{ECochG and audiometry}

Recently, Koka et al (2016) reported a correlation accounting for nearly $80 \%$ of the variability between physiologic thresholds of the first harmonic in the ECochG responses to tones and post-implantation audiometric thresholds in adults where hearing preservation was a goal. The ECochG responses were recorded through the implant contacts after implantation and activation. A particular strength of the study was that the ECochG and audiogram were obtained at the same time using the same in-ear probe-tube calibration obtained just prior to stimulation. The strong correlation indicates that an important role for ECochG could be hearing assessment in CI subjects unable to produce a behavioral threshold. Here, we showed a similar but weaker correlation between ECochG and audiometric thresholds obtained prior to implantation $\left(\mathrm{r}^{2}=0.42\right)$. Results similar to ours were obtained by Abbas et al. (2017), also comparing ECochG with clinically obtained audiometric thresholds.

In all studies to date, including the Koka et al (2016) study with well-controlled calibrations, the ECochG and audiometric thresholds were not just correlated but were often nearly equivalent, and some ECochG thresholds were lower than the behavioral. These results rule out a cause-and-effect relationship between ECochG and audiometric thresholds, since an evoked potential is by nature a sum of responding element while thresholds typically depend on a very small number of responses. Physiological thresholds lower than behavioral further supports the idea that the ECochG is produced primarily by hair cell sources distinct from those that lead to the audiometric thresholds.

\section{Accounting for outliers}

Evaluation of the ECochG waveforms from outliers excluded from the regression analyses indicated that these can be divided into three types. Two types had word scores outcomes that were lower than expected from the TR but were distinguished by either low $(<2)$ or high $(>=2)$ nerve scores. The cases with a low nerve score suggests that the outcomes could be limited by a neural deficiency. In contrast, a physiological explanation for the poor performance of subjects with a high TR and nerve category is not readily available. Performance in these subjects does not appear to be limited by their peripheral status. Therefore, in the clinical setting, ECochG results could be used to estimate the 'expected' result, and in cases of deficits, prompt the treatment team to investigate patient and device variables, such as electrode placement, map settings, or usage issues that may be limiting the performance.

The third outlier group, seen only in seen only in younger children (Fig. 5B), had a low or even absent TR but a high word score outcomes. The two children in this group, as described earlier, had etiologies (meningitis, connexin) where the cochlea could be affected, but the nerve spared. 


\section{Possibilities to account for remaining variability}

The TR accounted for a large fraction of variability in speech perception outcomes in adults and older children, but more than $50 \%$ of variability remains unexplained. Although we expected the addition of nerve score to improve the correlation of ECochG information with speech perception outcomes, this result was not found. It may be that this subjective measurement is too crude, and better quantification of the neural activity will reveal a benefit (see T. E. Fontenot et al. 2017 for a recent attempt). It is also apparent that the subset of CI subjects with preserved hearing that are currently being implanted due to expanded criteria have an advantage in noise compared to conventional CI subjects with profound hearing loss (Adunka et al. 2013; Gifford et al. 2013; Kiefer et al. 2005). The SP is another potential that varies greatly among CI subjects (e.g., Fig. 4), indicative of differences in source contributions. Thus, it remains possible that when more of the information is extracted from the ECochG signal it will increase the amount of variability in speech perception accounted for compared to the TR alone.

Some uncertainty in the measurement of the TR must be expected since it is obtained in the intraoperative environment at a single time point. In general, the placement of this recording probe is uniform across cases, because after removing part of the bony overhang the electrode can be wedged in the round window niche where it sits adjacent to the RW. Care must be taken that the RW niche is wet, either with natural fluids or saline. A dry recording site can usually be identified by a high surface impedance. However, the intraoperative recording environment is challenging, and cochlear malformations can affect electrode placement, the sound tube can be blocked with a clamp or the earphone become dislodged, etc. Because consistency in recording is so important it is worthwhile to consider using an initial transtympanic recording prior to surgery. Recordings from the promontory are only slightly lower than from the round window (Giardina et al. 2018), and transtympanic round window recordings themselves are also possible (Gibson 2007). Adding a preoperative ECochG procedure would have the additional advantage that it would come earlier than the intraoperative recordings, and thus provide the prognostic benefits in a more timely manner. The intraoperative recordings could also be used as a test-retest to verify the ECochG results from two locations.

Imprecision in the outcome measure is also an important issue. The CNC test at six months for adults is commonly used due to the relatively low ceiling effects, and because it is when most adult subjects begin to plateau in their speech perception performance (Gifford et al. 2008). Instead of using a single time point, further studies can use a sigmoid trajectory based on several time points, which should be more reliable (Holden et al. 2013). For the elderly the trajectory to a plateau can take longer, which can account for the difference between the elderly and other adults reported here (Dillon et al. 2013).

There are a number of other factors that could be combined in a multivariate approach with the ECochG, including surgical approach (round window vs. cochleostomy), electrode type (lateral wall or perimodiolar), electrode location/trauma (scala tympani only vs. other scala included), mode of stimulation (unilateral or bilateral, CI only or hearing preservation), the frequency mapping applied to the contacts, and cognitive factors, to yield a more complete model accounting for a majority of the variability. Additionally, ECochG could be valuable 
for facilitating future research regarding issues such as optimal surgical techniques, rehabilitative methods or device improvements. By accounting for a large portion of inherent variability, fewer subjects would be required to achieve the statistical power to demonstrate significance of small treatment effects.

\section{Future of ECochG in cochlear implantation}

The ECochG measurements provide a rich source of information about the wide variation in residual cochlear function of CI subjects. The measurements are simple, although the analyses to extract all of the available the information are complex. Currently, the measurements require a small amount of operating room time, but in principle comparable measurements could be obtained prior to surgery by recording at the round window or the promontory through a transtympanic approach. The results from pre-implantation ECochG can thus be used to better manage expectations of possible benefits to be gained from a CI, identify subjects performing below expectations, and devise rehabilitation approaches appropriate to individual physiology. The current results indicate that for subjects older than five years a very low TR is indicative of an outcome likely to be poor enough that additional perceptual modalities, such as lip-reading and/or use of additional assistive listening devices, should be encouraged. At the other extreme, a very high TR is indicative that excellent performance should be expected. If only average performance is obtained the collection of additional information may reveal a factor that can be alleviated or improved. Between the extremes, where most subjects are, further investigation into sources of outcome variability that add to that available from the TR is needed. While ECochG is a less reliable indicator of outcomes in children $<6$ years old, it can provide useful information in the context of particular etiologies and genetic backgrounds.

In addition to the information from ECochG that can be obtained pre-implantation, it can also be used intraoperatively during and immediately after insertion to examine the acute effect of implantation (Acharya et al. 2016; Campbell et al. 2015; Dalbert et al. 2015; Giardina et al. 2018; Harris et al. 2017; Kim et al. 2017) and post-implantation recorded through the implant contacts to follow the ongoing status of elements responding to sound (Abbas et al. 2017; Acharya et al. 2016; Kim et al. 2017; Koka et al. 2017; Koka et al. 2016). Thus, ECochG is becoming an important source of information for a variety of aspects of cochlear implantation.

\section{ACKNOWLEDGEMENTS}

Supported by NIH, (NIDCD grants 5T32DC005360-12 and 1-F30-DC-015168), and a grant from the MED EL Corporation. We thank Stephen H. Pulver for technical assistance.

T.E.F, and D.C.F. designed and performed experiments, analyzed data and wrote the paper; M.T.D. M.A.R collected and analyzed the audiological data in adults and edited versions of the paper; H.F.T. and L.R.P. collected and analyzed the audiological data in children and edited versions of the paper; O.F.A. and C.A.B. designed and performed experiments and edited versions of the paper; C.K.G., K.D.B and H.C.P. performed experiments and edited versions of the paper. 


\section{REFERENCES}

Abbas PJ, Tejani VD, Scheperle RA, et al. (2017). Using Neural Response Telemetry to Monitor Physiological Responses to Acoustic Stimulation in Hybrid Cochlear Implant Users. Ear Hear, 38, 409-425. [PubMed: 28085738]

Acharya AN, Tavora-Vieira D, Rajan GP (2016). Using the Implant Electrode Array to Conduct Realtime Intraoperative Hearing Monitoring During Pediatric Cochlear Implantation: Preliminary Experiences. Otol Neurotol, 37, e148-153. [PubMed: 26756149]

Adunka OF, Dillon MT, Adunka MC, et al. (2013). Hearing preservation and speech perception outcomes with electric-acoustic stimulation after 12 months of listening experience. Laryngoscope, 123, 2509-2515. [PubMed: 23918623]

Ahmad FI, Demason CE, HF BT, et al. (2012). Cochlear implantation in children with postlingual hearing loss. Laryngoscope.

Aminpour S, Tinling SP, Brodie HA (2005). Role of tumor necrosis factor-alpha in sensorineural hearing loss after bacterial meningitis. Otol Neurotol, 26, 602-609. [PubMed: 16015154]

Anderson CA, Lazard DS, Hartley DE (2016). Plasticity in bilateral superior temporal cortex: Effects of deafness and cochlear implantation on auditory and visual speech processing. Hear Res.

Baumgartner WD, Pok SM, Egelierler B, et al. (2002). The role of age in pediatric cochlear implantation. Int J Pediatr Otorhinolaryngol, 62, 223-228. [PubMed: 11852125]

Benasich AA, Choudhury NA, Realpe-Bonilla T, et al. (2014). Plasticity in developing brain: active auditory exposure impacts prelinguistic acoustic mapping. J Neurosci, 34, 13349-13363. [PubMed: 25274814]

Blamey P (1997). Are spiral ganglion cell numbers important for speech perception with a cochlear implant? Am. J. Otolaryngol, 18, S11-12.

Blamey P, Arndt P, Bergeron F, et al. (1996). Factors affecting auditory performance of postlinguistically deaf adults using cochlear implants. Audiol. Neurootol, 1, 293-306. [PubMed: 9390810]

Blamey P, Artieres F, Baskent D, et al. (2013). Factors affecting auditory performance of postlinguistically deaf adults using cochlear implants: an update with 2251 patients. Audiol Neurootol, 18, 36-47. [PubMed: 23095305]

Blamey P, Sarant JZ, Paatsch LE, et al. (2001). Relationships among speech perception, production, language, hearing loss, and age in children with impaired hearing. J Speech Lang Hear Res, 44, 264-285. [PubMed: 11324650]

Boons T, Brokx JP, Frijns JH, et al. (2012). Effect of pediatric bilateral cochlear implantation on language development. Arch Pediatr Adolesc Med, 166, 28-34. [PubMed: 22213747]

Buchman CA, Roush PA, Teagle HF, et al. (2006). Auditory neuropathy characteristics in children with cochlear nerve deficiency. Ear Hear, 27, 399-408. [PubMed: 16825889]

Campbell L, Kaicer A, Briggs R, et al. (2015). Cochlear response telemetry: intracochlear electrocochleography via cochlear implant neural response telemetry pilot study results. Otol Neurotol, 36, 399-405. [PubMed: 25473960]

Cohen LT (2009). Practical model description of peripheral neural excitation in cochlear implant recipients: 1. Growth of loudness and ECAP amplitude with current. Hear Res, 247, 87-99. [PubMed: 19063956]

Dalbert A, Pfiffner F, Roosli C, et al. (2015). Extra- and Intracochlear Electrocochleography in Cochlear Implant Recipients. Audiol Neurootol, 20, 339-348. [PubMed: 26340649]

Dallos P (1973). The Auditory Periphery Biophysics and Physiology. New York: Academic Press, Inc.

Dallos P, Schoeny ZG, Cheatham MA (1972). Cochlear summating potentials. Descriptive aspects. Acta Otolaryngol Suppl, 302, 1-46. [PubMed: 4354496]

Davidson LS, Geers AE, Blamey PJ, et al. (2011). Factors contributing to speech perception scores in long-term pediatric cochlear implant users. Ear Hear, 32, 19S-26S. [PubMed: 21832887]

Davis H, Deatherage BH, Eldredge DH, et al. (1958). Summating potentials of the cochlea. Am J Physiol, 195, 251-261. [PubMed: 13583157] 
DeVries L, Scheperle R, Bierer JA (2016). Assessing the Electrode-Neuron Interface with the Electrically Evoked Compound Action Potential, Electrode Position, and Behavioral Thresholds. J Assoc Res Otolaryngol, 17, 237-252. [PubMed: 26926152]

Dillon MT, Buss E, Adunka MC, et al. (2013). Long-term speech perception in elderly cochlear implant users. JAMA Otolaryngol Head Neck Surg, 139, 279-283. [PubMed: 23657352]

Dowell RC, Dettman SJ, Blamey PJ, et al. (2002). Speech perception in children using cochlear implants: prediction of long-term outcomes. Cochlear Implants Int, 3, 1-18. [PubMed: 18792108]

Dunn CC, Walker EA, Oleson J, et al. (2014). Longitudinal speech perception and language performance in pediatric cochlear implant users: the effect of age at implantation. Ear Hear, 35, 148-160. [PubMed: 24231628]

Durrant JD, Wang J, Ding DL, et al. (1998). Are inner or outer hair cells the source of summating potentials recorded from the round window? J Acoust Soc Am, 104, 370-377. [PubMed: 9670530]

Finley CC, Holden TA, Holden LK, et al. (2008). Role of electrode placement as a contributor to variability in cochlear implant outcomes. Otol Neurotol, 29, 920-928. [PubMed: 18667935]

Fitzpatrick DC, Campbell AT, Choudhury B, et al. (2014). Round window electrocochleography just before cochlear implantation: relationship to word recognition outcomes in adults. Otol Neurotol, 35, 64-71. [PubMed: 24317211]

Fontenot TE, Giardina CK, Fitzpatrick DC (2017). A Model-Based Approach for Separating the Cochlear Microphonic from the Auditory Nerve Neurophonic in the Ongoing Response Using Electrocochleography. Front Neurosci, 11, 592. [PubMed: 29123468]

Fontenot TE, Giardina CK, Fitzpatrick DC (2017). A Model-Based Method for Separating The Cochlear Microphonic From The Auditory Nerve Neurophonic in The Ongoing Response to Tones In Electrocochleography. Frontiers in Neuroscience, In Press.

Forgues M, Koehn HA, Dunnon AK, et al. (2014). Distinguishing hair cell from neural potentials recorded at the round window. J Neurophysiol, 111, 580-593. [PubMed: 24133227]

Formeister EJ, McClellan JH, Merwin WH 3rd, et al. (2015). Intraoperative round window electrocochleography and speech perception outcomes in pediatric cochlear implant recipients. Ear Hear, 36, 249-260. [PubMed: 25259669]

Friedland DR, Runge-Samuelson C, Baig H, et al. (2010). Case-control analysis of cochlear implant performance in elderly patients. Arch Otolaryngol Head Neck Surg, 136, 432-438. [PubMed: 20479370]

Geers A, Brenner C, Davidson L (2003). Factors associated with development of speech perception skills in children implanted by age five. Ear and Hearing, 24, 24s-35s. [PubMed: 12612478]

Geers AE, Brenner CA, Tobey EA (2011). Long-term outcomes of cochlear implantation in early childhood: sample characteristics and data collection methods. Ear Hear, 32, 2S-12S.

Gervain J (2015). Plasticity in early language acquisition: the effects of prenatal and early childhood experience. Curr Opin Neurobiol, 35, 13-20. [PubMed: 26093365]

Giardina CK, Fontenot TE, Pulver SH, et al. (2018). Response Changes during Insertion of a Cochlear Implant using Extracochlear Electrocochleography Ear and Hearing, In Revision.

Gibson WP (2007). Electrocochleography In Vestibular Disorders. Sydney: Scott Edgars.

Gifford RH, Dorman MF, Shallop JK, et al. (2010). Evidence for the expansion of adult cochlear implant candidacy. Ear Hear, 31, 186-194. [PubMed: 20071994]

Gifford RH, Dorman MF, Skarzynski H, et al. (2013). Cochlear implantation with hearing preservation yields significant benefit for speech recognition in complex listening environments. Ear Hear, 34, 413-425. [PubMed: 23446225]

Gifford RH, Shallop JK, Peterson AM (2008). Speech recognition materials and ceiling effects: considerations for cochlear implant programs. Audiol Neurootol, 13, 193-205. [PubMed: 18212519]

Green SH, Bailey E, Wang Q, et al. (2012). The Trk A, B, C's of neurotrophins in the cochlea. Anat Rec (Hoboken), 295, 1877-1895. [PubMed: 23044862]

Harris MS, Riggs WJ, Koka K, et al. (2017). Real-Time Intracochlear Electrocochleography Obtained Directly Through a Cochlear Implant. Otol Neurotol, 38, e107-e113. [PubMed: 28498269] 
Haskins H (1949). A phonetically balanced test of speech discrimitation for children.. In. Evanston, IL. : Northwestern University.

He W, Porsov E, Kemp D, et al. (2012). The group delay and suppression pattern of the cochlear microphonic potential recorded at the round window. PLoS One, 7, e34356. [PubMed: 22470560]

Henry KR (1995). Auditory nerve neurophonic recorded from the round window of the Mongolian gerbil. Hear Res, 90, 176-184. [PubMed: 8974995]

Holden LK, Finley CC, Firszt JB, et al. (2013). Factors Affecting Open-Set Word Recognition in Adults With Cochlear Implants. Ear Hear.

Holden LK, Firszt JB, Reeder RM, et al. (2016). Factors Affecting Outcomes in Cochlear Implant Recipients Implanted With a Perimodiolar Electrode Array Located in Scala Tympani. Otol Neurotol, 37, 1662-1668. [PubMed: 27755365]

Joris PX, Verschooten E (2013). On the limit of neural phase locking to fine structure in humans. Adv Exp Med Biol, 787, 101-108. [PubMed: 23716214]

Kamakura T, Nadol JB Jr. (2016). Correlation between word recognition score and intracochlear new bone and fibrous tissue after cochlear implantation in the human. Hear Res, 339, 132-141. [PubMed: 27371868]

Kang SY, Colesa DJ, Swiderski DL, et al. (2010). Effects of hearing preservation on psychophysical responses to cochlear implant stimulation. J Assoc Res Otolaryngol, 11, 245-265. [PubMed: 19902297]

Khan AM, Whiten DM, Nadol JB Jr., et al. (2005). Histopathology of human cochlear implants: correlation of psychophysical and anatomical measures. Hear Res, 205, 83-93. [PubMed: 15953517]

Kiang NY, Moxon EC (1972). Physiological considerations in artificial stimulation of the inner ear. Ann Otol Rhinol Laryngol, 81, 714-730. [PubMed: 4651114]

Kiefer J, Pok M, Adunka O, et al. (2005). Combined electric and acoustic stimulation of the auditory system: results of a clinical study. Audiol Neurootol, 10, 134-144. [PubMed: 15724084]

Kim JR, Abbas PJ, Brown CJ, et al. (2010). The Relationship Between Electrically Evoked Compound Action Potential and Speech Perception: A Study in Cochlear Implant Users With Short Electrode Array. Otology \& Neurotology, 31, 1041-1048. [PubMed: 20634770]

Kim JR, Tejani VD, Abbas PJ, et al. (2017). Intracochlear Recordings of Acoustically and Electrically Evoked Potentials in Nucleus Hybrid L24 Cochlear Implant Users and Their Relationship to Speech Perception. Front Neurosci, 11, 216. [PubMed: 28469553]

Koka K, Litvak LM (2017). Feasibility of Using Electrocochleography for Objective Estimation of Electro-Acoustic Interactions in Cochlear Implant Recipients with Residual Hearing. Front Neurosci, 11, 337. [PubMed: 28674482]

Koka K, Saoji AA, Litvak LM (2016). Electrocochleography in Cochlear Implant Recipients With Residual Hearing: Comparison With Audiometric Thresholds. Ear Hear, 38, e161-e167.

Kujawa SG, Liberman MC (2009). Adding insult to injury: cochlear nerve degeneration after "temporary" noise-induced hearing loss. J Neurosci, 29, 14077-14085. [PubMed: 19906956]

Kujawa SG, Liberman MC (2015). Synaptopathy in the noise-exposed and aging cochlea: Primary neural degeneration in acquired sensorineural hearing loss. Hear Res, 330, 191-199. [PubMed: 25769437]

Lazard DS, Vincent C, Venail F, et al. (2012). Pre-, per- and postoperative factors affecting performance of postlinguistically deaf adults using cochlear implants: a new conceptual model over time. PLoS One, 7, e48739. [PubMed: 23152797]

Lee HJ, Giraud AL, Kang E, et al. (2007). Cortical activity at rest predicts cochlear implantation outcome. Cereb Cortex, 17, 909-917. [PubMed: 16731883]

Liberman MC, Epstein MJ, Cleveland SS, et al. (2016). Toward a Differential Diagnosis of Hidden Hearing Loss in Humans. PLoS One, 11, e0162726. [PubMed: 27618300]

Lichtenhan JT, Cooper NP, Guinan JJ Jr. (2013). A new auditory threshold estimation technique for low frequencies: proof of concept. Ear Hear, 34, 42-51. [PubMed: 22874644]

Lichtenhan JT, Hartsock JJ, Gill RM, et al. (2014). The Auditory Nerve Overlapped Waveform (ANOW) Originates in the Cochlear Apex. J Assoc Res Otolaryngol. 
Lin HW, Furman AC, Kujawa SG, et al. (2011). Primary neural degeneration in the Guinea pig cochlea after reversible noise-induced threshold shift. J Assoc Res Otolaryngol, 12, 605-616. [PubMed: 21688060]

McClellan JH, Formeister EJ, Merwin WH 3rd, et al. (2014). Round window electrocochleography and speech perception outcomes in adult cochlear implant subjects: comparison with audiometric and biographical information. Otol Neurotol, 35, e245-252. [PubMed: 25118584]

Moore DR, Shannon RV (2009). Beyond cochlear implants: awakening the deafened brain. Nat Neurosci, 12, 686-691. [PubMed: 19471266]

MSTB: The New Minimum Speech Test Battery. 2011 from http://www.auditorypotential.com/ MSTB_Nav.html.

Nadol JB Jr., Eddington DK (2006). Histopathology of the inner ear relevant to cochlear implantation. Adv Otorhinolaryngol, 64, 31-49. [PubMed: 16891835]

Niparko JK, Tobey EA, Thal DJ, et al. (2010). Spoken language development in children following cochlear implantation. JAMA, 303, 1498-1506. [PubMed: 20407059]

O'Connell BP, Cakir A, Hunter JB, et al. (2016). Electrode Location and Angular Insertion Depth Are Predictors of Audiologic Outcomes in Cochlear Implantation. Otol Neurotol, 37, 1016-1023. [PubMed: 27348391]

O'Connell BP, Holder JT, Dwyer RT, et al. (2017). Intra- and Postoperative Electrocochleography May Be Predictive of Final Electrode Position and Postoperative Hearing Preservation. Front Neurosci, 11, 291. [PubMed: 28611574]

Peterson GE, Lehiste I (1962). Revised CNC lists for auditory tests. J Speech Hear Disord, 27, 62-70. [PubMed: 14485785]

Pfingst BE, Zhou N, Colesa DJ, et al. (2015). Importance of cochlear health for implant function. Hear Res, 322, 77-88. [PubMed: 25261772]

Ramekers D, Versnel H, Strahl SB, et al. (2014). Auditory-nerve responses to varied inter-phase gap and phase duration of the electric pulse stimulus as predictors for neuronal degeneration. J Assoc Res Otolaryngol, 15, 187-202. [PubMed: 24469861]

Riggs WJ, Roche JP, Giardina CK, et al. (2017). Intraoperative Electrocochleographic Characteristics of Auditory Neuropathy Spectrum Disorder in Cochlear Implant Subjects. Front Neurosci, 11, 416. [PubMed: 28769753]

Riggs WJ, Roche JR, Giardina CK, et al. (2017). Intraoperative Electrocochleographic Characteristics of Auditory Neuropathy Spectrum Disorder In Cochlear Implant Subjects In. Frontiers in Neuroscience, in press.

Roberts DS, Lin HW, Herrmann BS, et al. (2013). Differential cochlear implant outcomes in older adults. Laryngoscope, 123, 1952-1956. [PubMed: 23737286]

Rose JE, Brugge JF, Anderson DJ, et al. (1967). Phase-locked response to low-frequency tones in single auditory nerve fibers of the squirrel monkey. J Neurophysiol, 30, 769-793. [PubMed: 4962851]

Rubinstein JT, Parkinson WS, Tyler RS, et al. (1999). Residual speech recognition and cochlear implant performance: effects of implantation criteria. Am J Otolaryngol, 20, 445-452.

Schuknecht HF, Merchant SN, Nadol JB (2010). Schuknecht's pathology of the ear. (3rd ed.). Shelton, CT: People's Medical Pub. House-USA.

Scott WC, Giardina CK, Pappa AK, et al. (2016). The Compound Action Potential in Subjects Receiving a Cochlear Implant. Otol Neurotol, 37, 1654-1661. [PubMed: 27749750]

Sellick P, Patuzzi R, Robertson D (2003). Primary afferent and cochlear nucleus contributions to extracellular potentials during tone-bursts. Hear Res, 176, 42-58. [PubMed: 12583880]

Seyyedi M, Viana LM, Nadol JB Jr. (2014). Within-subject comparison of word recognition and spiral ganglion cell count in bilateral cochlear implant recipients. Otol Neurotol, 35, 1446-1450. [PubMed: 25120196]

Sininger Y (2008). Guidelines Development Conference on the Identification and Management of Infants with Auditory Neuropathy In Northern J (Ed.), International Newborn Hearing Screening Conference. Como, Italy: Retrieved from https://www.childrenscolorado.org/globalassets/ departments/ear-nose-throat/ansd-monograph.pdf. 
Snyder RL, Schreiner CE (1984). The auditory neurophonic: basic properties. Hear Res, 15, 261-280. [PubMed: 6501114]

Snyder RL, Schreiner CE (1985). Forward masking of the auditory nerve neurophonic (ANN) and the frequency following response (FFR). Hear Res, 20, 45-62. [PubMed: 4077744]

Strahl SB, Ramekers D, Nagelkerke MM, et al. (2016). Assessing the Firing Properties of the Electrically Stimulated Auditory Nerve Using a Convolution Model. Adv Exp Med Biol, 894, 143-153. [PubMed: 27080655]

Strelnikov K, Rouger J, Demonet JF, et al. (2010). Does brain activity at rest reflect adaptive strategies? Evidence from speech processing after cochlear implantation. Cereb Cortex, 20, 12171222. [PubMed: 19805418]

Suzuki J, Corfas G, Liberman MC (2016). Round-window delivery of neurotrophin 3 regenerates cochlear synapses after acoustic overexposure. Sci Rep, 6, 24907. [PubMed: 27108594]

Teagle HFB, Roush PA, Woodard JS, et al. (2010). Cochlear Implantation in Children with Auditory Neuropathy Spectrum Disorder. Ear and Hearing, 31, 325-335. [PubMed: 20090530]

van Eijl RH, Buitenhuis PJ, Stegeman I, et al. (2017). Systematic review of compound action potentials as predictors for cochlear implant performance. Laryngoscope, 127, 476-487. [PubMed: 27804133]

van Emst MG, Klis SF, Smoorenburg GF (1995). Tetraethylammonium effects on cochlear potentials in the guinea pig. Hear Res, 88, 27-35. [PubMed: 8576000]

Verschooten E, Joris PX (2014). Estimation of neural phase locking from stimulus-evoked potentials. J Assoc Res Otolaryngol, 15, 767-787. [PubMed: 24890715]

Verschooten E, Robles L, Desloovere C, et al. (2013). Assessment of Neural Phase-Locking at the Round Window in Human. Assoc. Res. Otolaryngol. Abs, 426.

Verschooten E, Robles L, Joris PX (2015). Assessment of the limits of neural phase-locking using mass potentials. J Neurosci, 35, 2255-2268. [PubMed: 25653380]

Wang NY, Eisenberg LS, Johnson KC, et al. (2008). Tracking development of speech recognition: Longitudinal data from hierarchical assessments in the childhood development after cochlear implantation study. Otology \& Neurotology, 29, 240-245. [PubMed: 18223451]

Weiss TF, Rose C (1988). A comparison of synchronization filters in different auditory receptor organs. Hear Res, 33, 175-179. [PubMed: 3397327]

Wingard JC, Zhao HB (2015). Cellular and Deafness Mechanisms Underlying Connexin MutationInduced Hearing Loss - A Common Hereditary Deafness. Front Cell Neurosci, 9, 202. [PubMed: 26074771]

Zheng XY, Ding DL, McFadden SL, et al. (1997). Evidence that inner hair cells are the major source of cochlear summating potentials. Hear Res, 113, 76-88. [PubMed: 9387987]

Zhou N, Kraft CT, Colesa DJ, et al. (2015). Integration of Pulse Trains in Humans and Guinea Pigs with Cochlear Implants. J Assoc Res Otolaryngol, 16, 523-534. [PubMed: 25990549]

Zhou N, Pfingst BE (2016). Evaluating multipulse integration as a neural-health correlate in human cochlear-implant users: Relationship to forward-masking recovery. J Acoust Soc Am, 139, EL70-75. [PubMed: 27036290] 


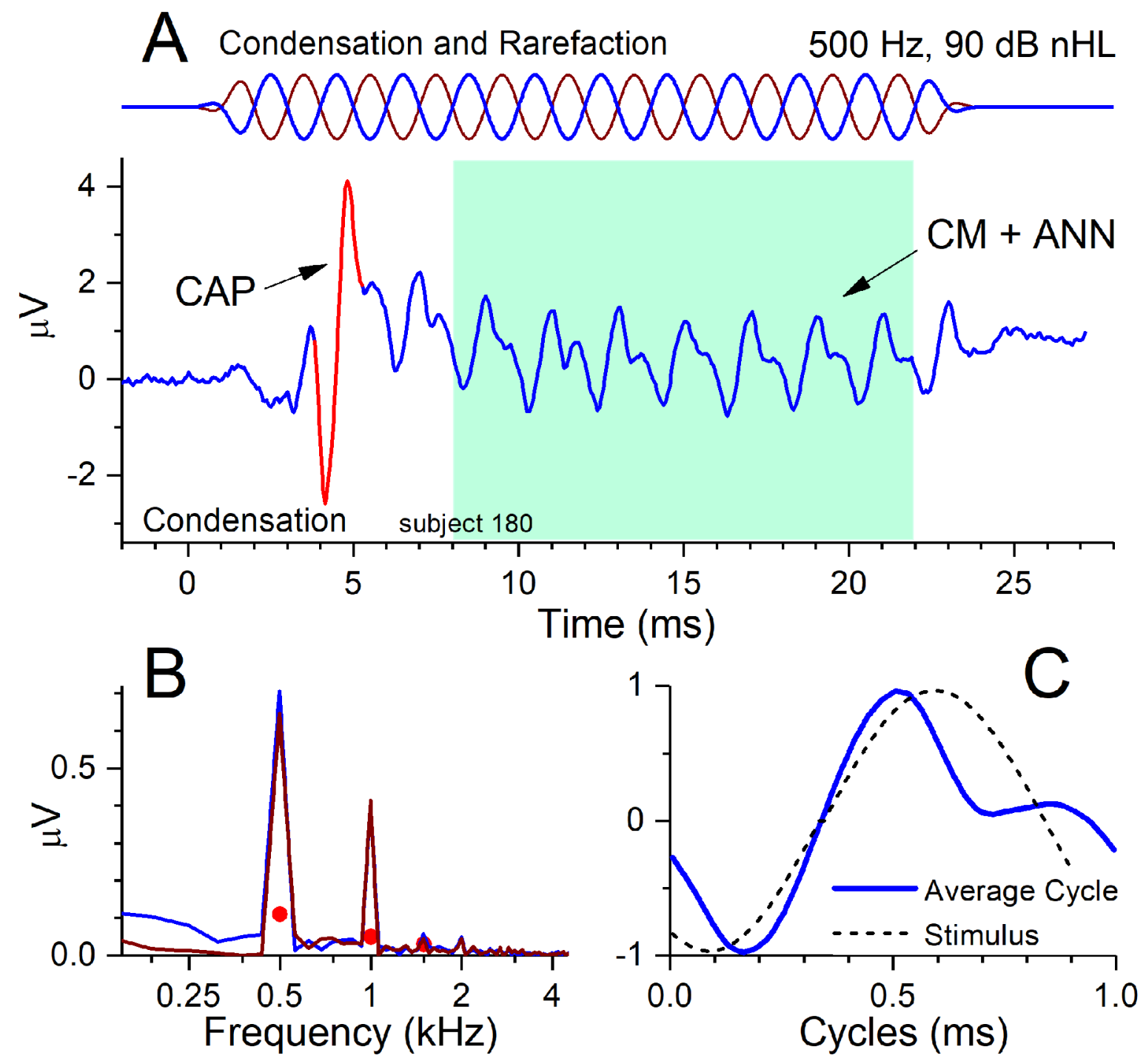

Figure 1.

Example of an ECochG response to a $500 \mathrm{~Hz}$ tone burst at $90 \mathrm{~dB} \mathrm{nHL}$. (A) The stimulus (top) was presented in alternating condensation and rarefaction phases. The time waveform shows a CAP (arrow) to the stimulus onset and the ongoing response to the tone (shaded box). To the extent the cochlea retains neural responses to sound this ongoing portion can contain an ANN in addition the CM (see text). This case contained an ANN, as indicated by the spectral and temporal response patterns. (B) The spectral pattern shows peaks above the level of significance (filled circles) to harmonics 1-3 (500, 1000 and $1500 \mathrm{~Hz})$. While the $\mathrm{CM}$ and ANN both produce even and odd harmonics, such a large second harmonic is indicative of neural activity. (C) The temporal pattern is shown as an 'average cycle' (solid line) that was obtained by averaging each cycle of the ongoing response. A representation of the stimulus (dashed line) is shown for comparison, after being shifted in phase to the point where the correlation between stimulus and response was maximal. The distortion in the average cycle is not consistent with those produced by the CM due to saturation (see text), and is thus affected by the ANN. 
A

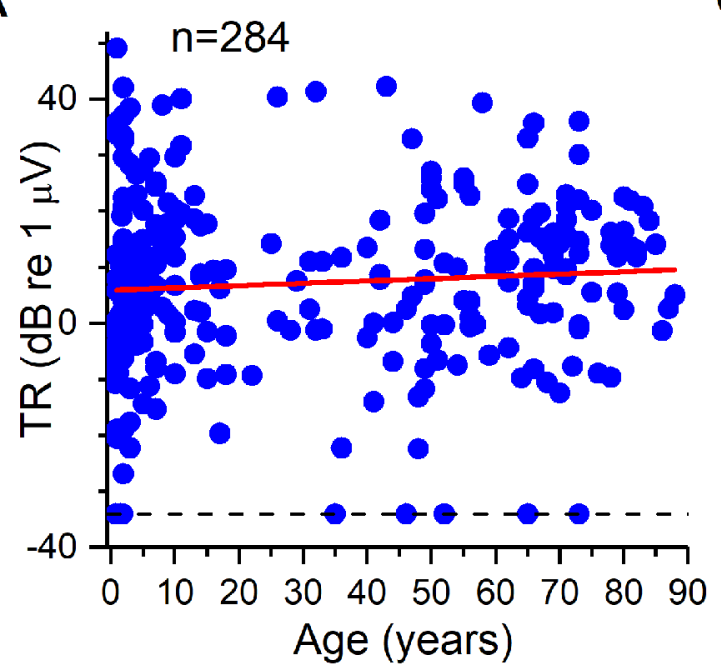

B

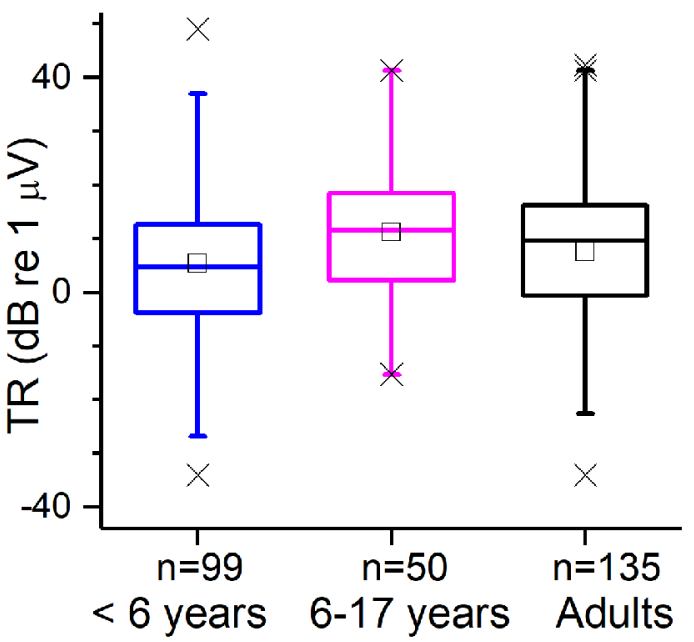

C

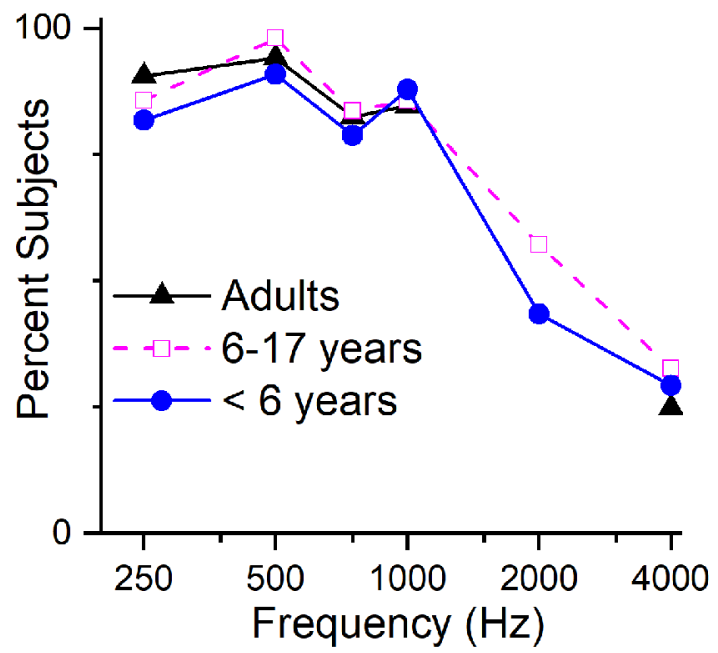

$\mathrm{D}$

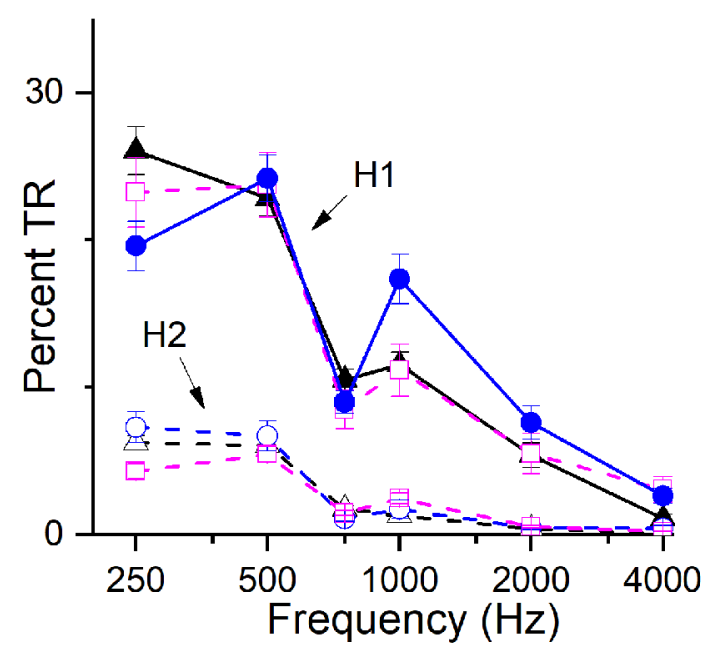

Figure 2.

Distributions of ECochG responses. (A) TR as a function of age. The TR spanned a wide range for all age groups, from infants to the elderly. The regression line (red) showed no significant trend with age $\left(\mathrm{r}^{2}=0.006, \mathrm{p}=0.19\right)$. (B) Boxplot of TR distribution by age group. Bars represent median values, squares are the means, boxes are the semi-interquartile range, whiskers are to $99 \%$ of the distributions and X's are the maximum and minimum values and values outside $99 \%$. There was a small but significant (see text) trend between the groups for the youngest children to have a smaller TR (C) Proportion of the subject population in each age group with a significant response to each of the tested frequencies. A high proportion of subjects had responses from 250-1000 Hz, and lower proportions for 2000 and $4000 \mathrm{~Hz}$. (D) The percent of the TR contributed by each frequency for the first (solid lines) and second (dashed lines) harmonics ( $\mathrm{H} 1$ and $\mathrm{H} 2$ ). The $\mathrm{HI}$ contributed a larger fraction than the $\mathrm{H} 2$ across all frequencies, and both the $\mathrm{H} 1$ and $\mathrm{H} 2$ were larger for 250 and $500 \mathrm{~Hz}$ than the other frequencies. Although not a clean separation, the CM is primarily in $\mathrm{H} 1$, and the ANN, if present, will increase the $\mathrm{H} 2$. Thus, the $\mathrm{CM}$ appeared to be the largest fraction of the response, even to the lowest frequencies where the ANN would be expected to be the largest. 
To compute these percentages, the magnitude at each frequency was divided by the TR and multiplied by 100 to produce a percentage; results shown are the means and standard errors of these percentages across all cases, with $-34 \mathrm{~dB}(0.02 \mathrm{uV})$ inserted for all cases without a significant response (proportion with no response was the data shown in $\mathrm{C}$ subtracted from $100)$. 


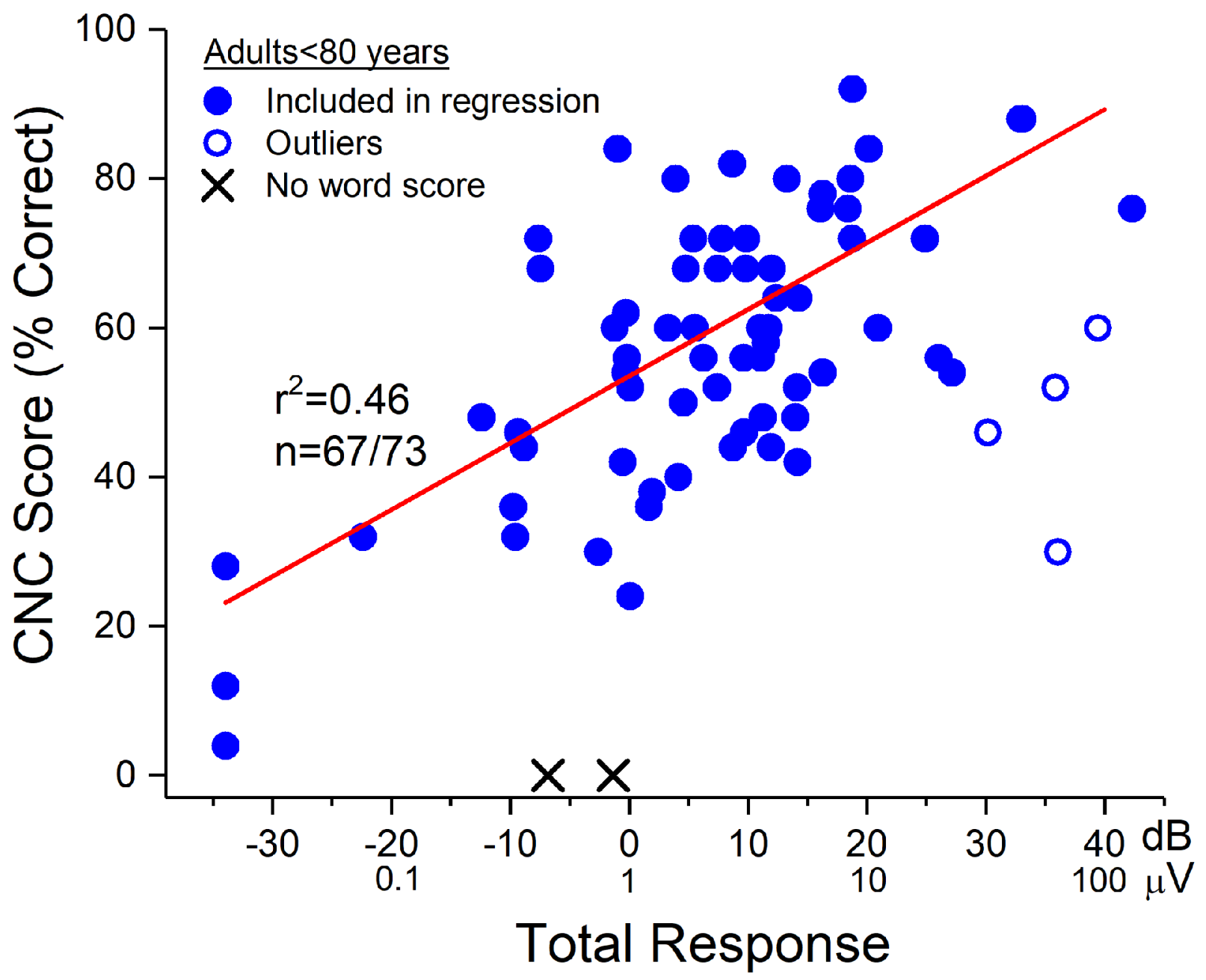

Figure 3.

TR vs. CNC word score results at 6 months post-activation in adult CI subjects $<80$ years old. The regression data shown is based on the group of subjects indicated by the filled circles. The outliers (open circles) had lower CNC scores (poorer performance) than their TRs would indicate. Two subjects did not reach open-set speech perception testing at 6 months after the CI was activated (X symbols). 

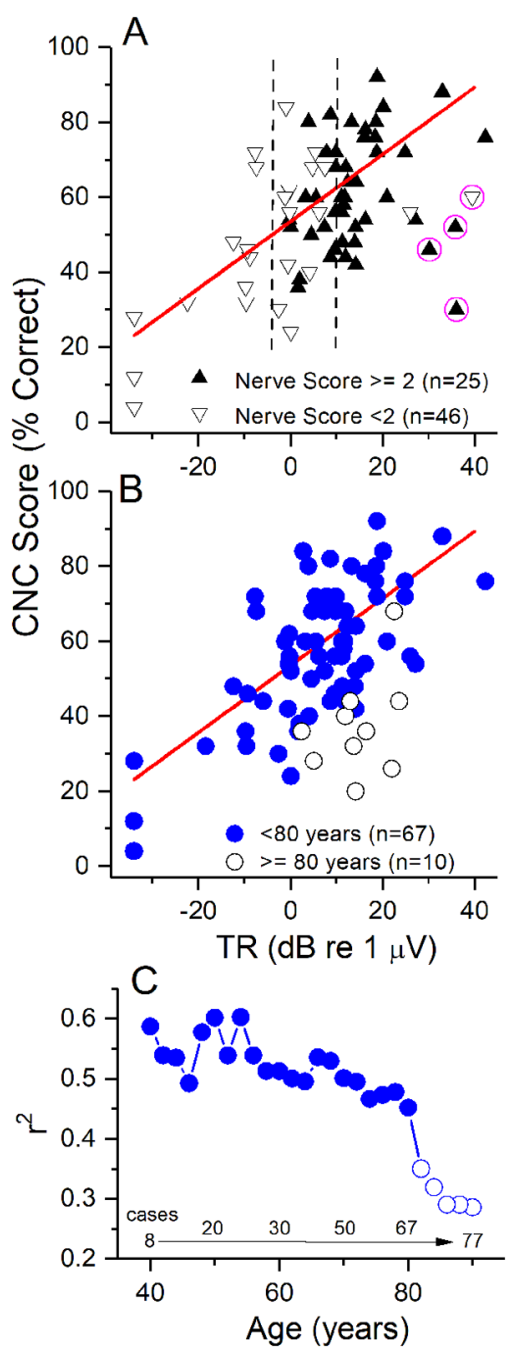

Figure 4.

Inclusion of nerve scores and the elderly. (A) Nerve scores. Cases with poor nerve scores (down triangles) were those with no evidence of ANN or CAP (nerve score $=0$ ), to one or the other being present but not prominent (nerve score =1). Cases with good nerve scores (up triangles were those where the CAP and ANN were present but not prominent, or one or the other was present and prominent (nerve score $=2$ ); to those where both were present and one was prominent (nerve score $=3$ ) to those where both were prominent (nerve score $=4$ ). Data is the same as in Fig. 3. Most case with large TRs (> $10 \mathrm{~dB}$ or $3.16 \mu \mathrm{V}$, right dashed line) had good nerve scores, while most cases with smalls with TRs $(<-6 \mathrm{~dB}$, or $0.5 \mathrm{uV})$ had poor nerve scores (down triangles). Cases in-between were mixed, but with no systematic distribution indicating poor nerve scores were associated with worse word score outcomes. (B) Addition of cases 80 years and older. For the younger adults only those cases included in the regression from Fig. 3are shown. Subjects 80 years and older generally had lower speech perceptions scores for a given TR, although there was overlap with the younger group. (C). A cumulative regression function where subjects with increasingly older ages were progressively added and the $r^{2}$ recalculated. The $r^{2}$ was $>0.45$ and relatively stable until subjects $\geq 80$ years old were included, at which point it abruptly declined, ending at $<0.3$. 


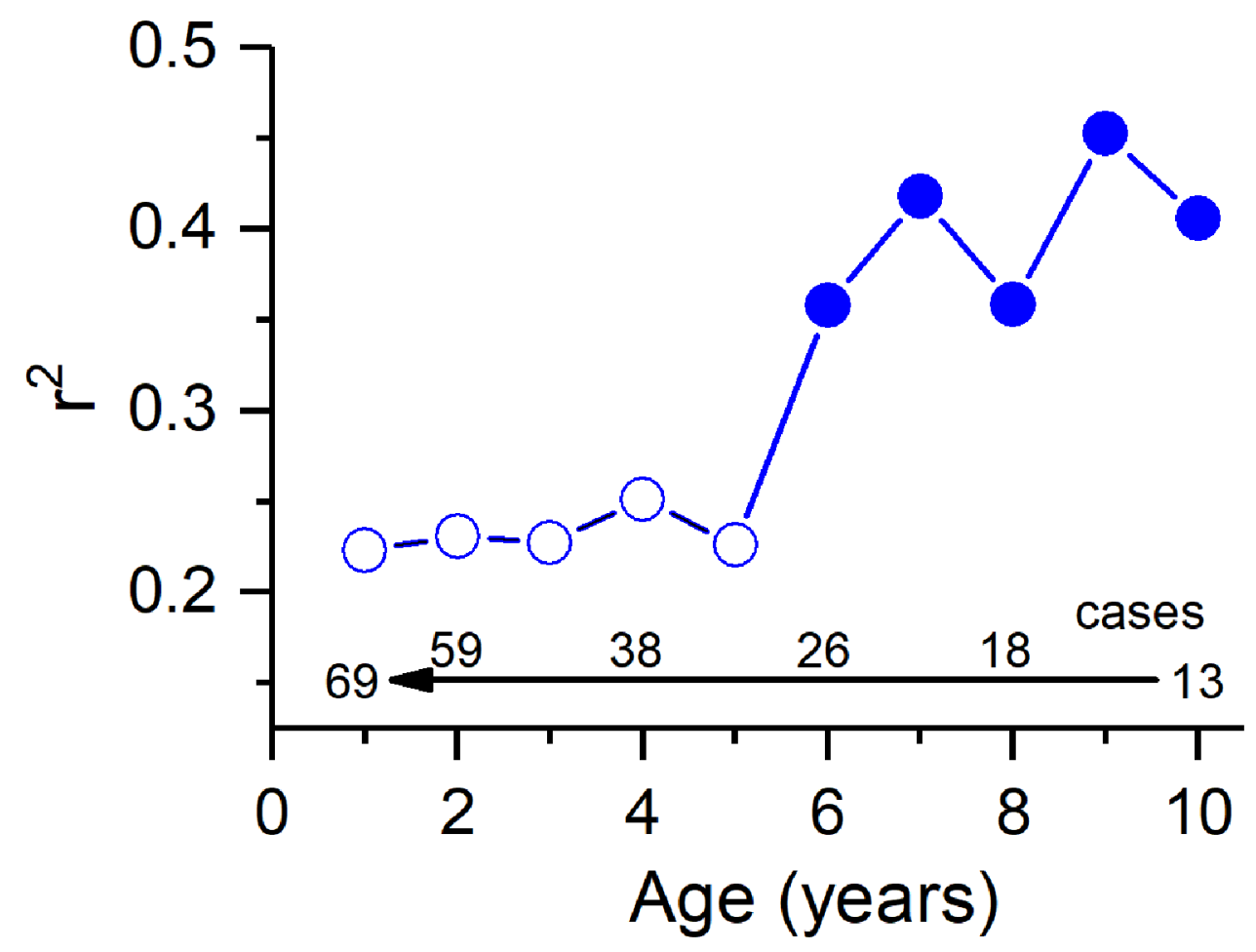

Figure 5.

A cumulative regression function where subjects with younger ages were progressively added and the $\mathrm{r}^{2}$ recalculated. For ages $6-18$ years the $\mathrm{r}^{2}$ was above about 0.35 , while inclusion of children younger than 6 caused a sharp decrease. As with the adults, this cohort excluded outliers and those who did not achieve word scores (see Fig. 6). 


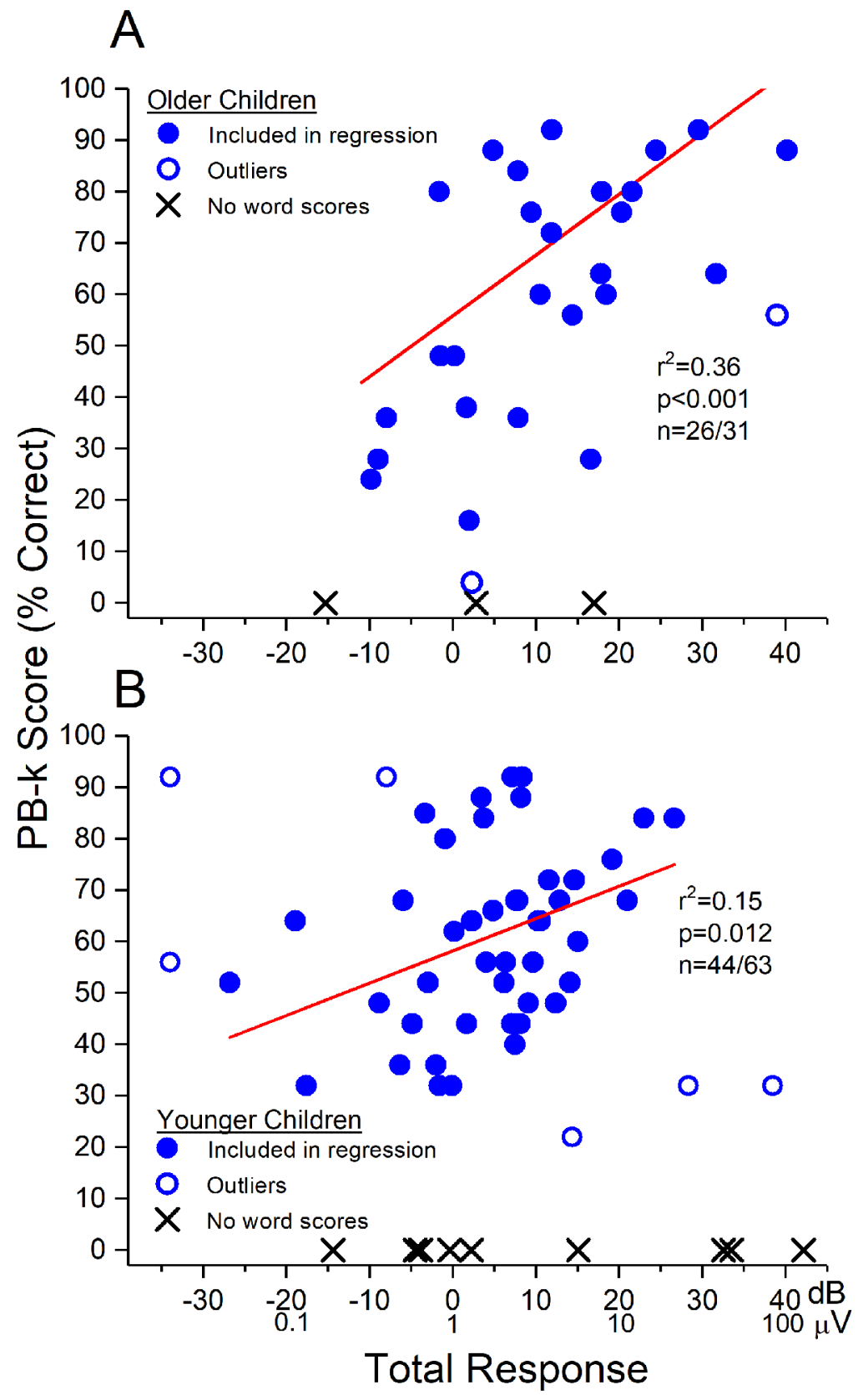

Figure 6.

TR vs. PB-k word score in pediatric subjects. (A) Subjects 6 years and older. (B) Subjects younger than 6 years. In both groups the regression lines include the cases with the filled circles. The $\mathrm{r}^{2}$ for the regression was 0.36 , but fell to 0.15 in the younger children. Both populations had outliers with word score outcomes lower than expected from their TR, similar to those identified in the adult population. An additional type of outlier was seen in the younger children where the TR was small or absent but the word score outcomes high or fairly high. There were many more cases with no word score results in the younger children compared to the older children or adults. 


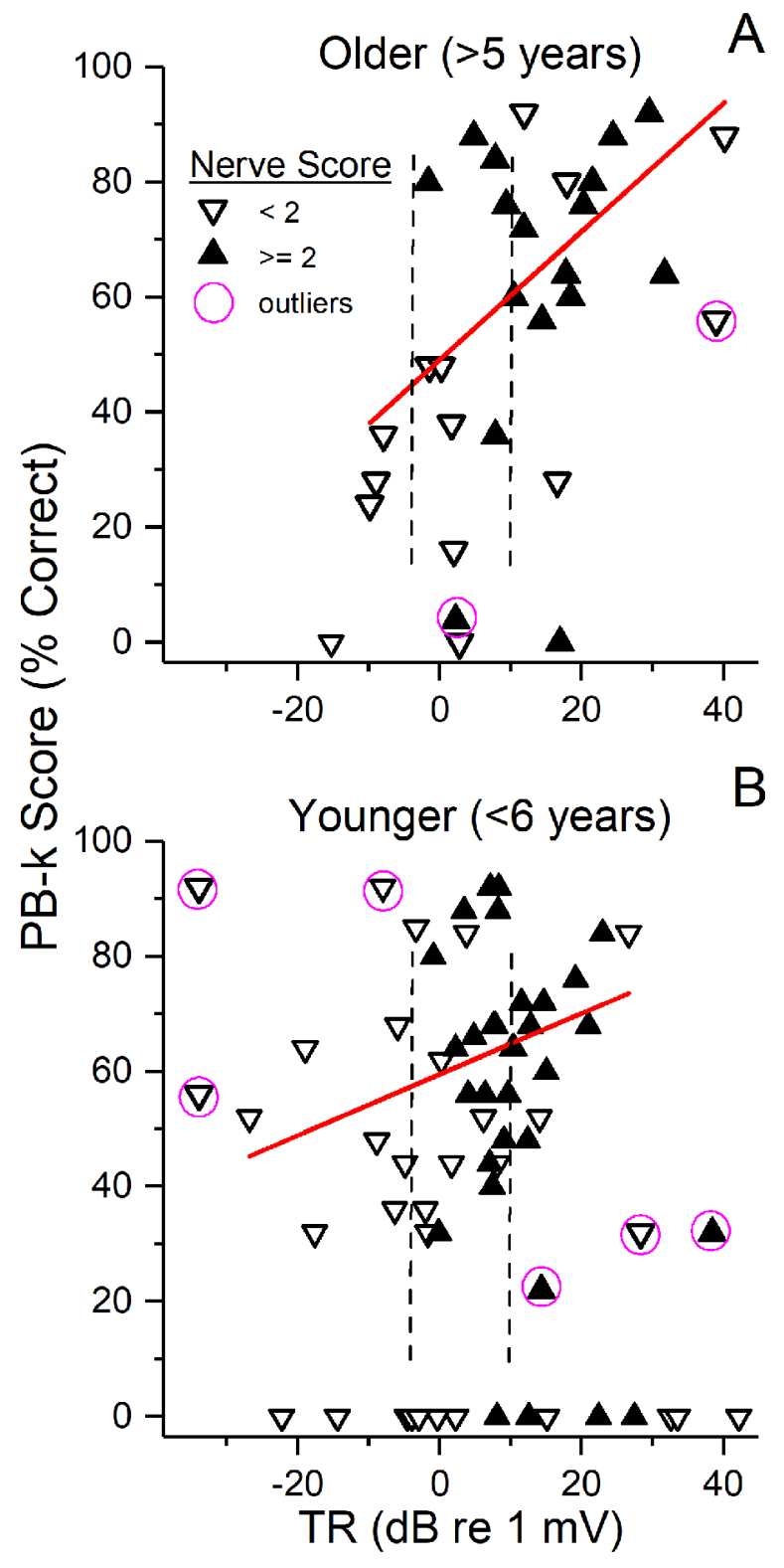

Figure 7.

Inclusion of nerve scores in children. (A) Subjects 6 years and older. (B) Subjects younger than 6 years. As with adults, most case with large TRs (>10 dB or about $3 \mu \mathrm{V}$, dotted line) showed a good nerve score, while cases with TR just below $10 \mathrm{~dB}$ were mixed, and cases below about $0 \mathrm{~dB}$ (1) all had only sinusoidal responses indicative of $\mathrm{CM}$ with no CAP; i.e., were poor nerve. Unlike adults, case with no word scores often had TRs large enough for neural activity to be evaluated. 


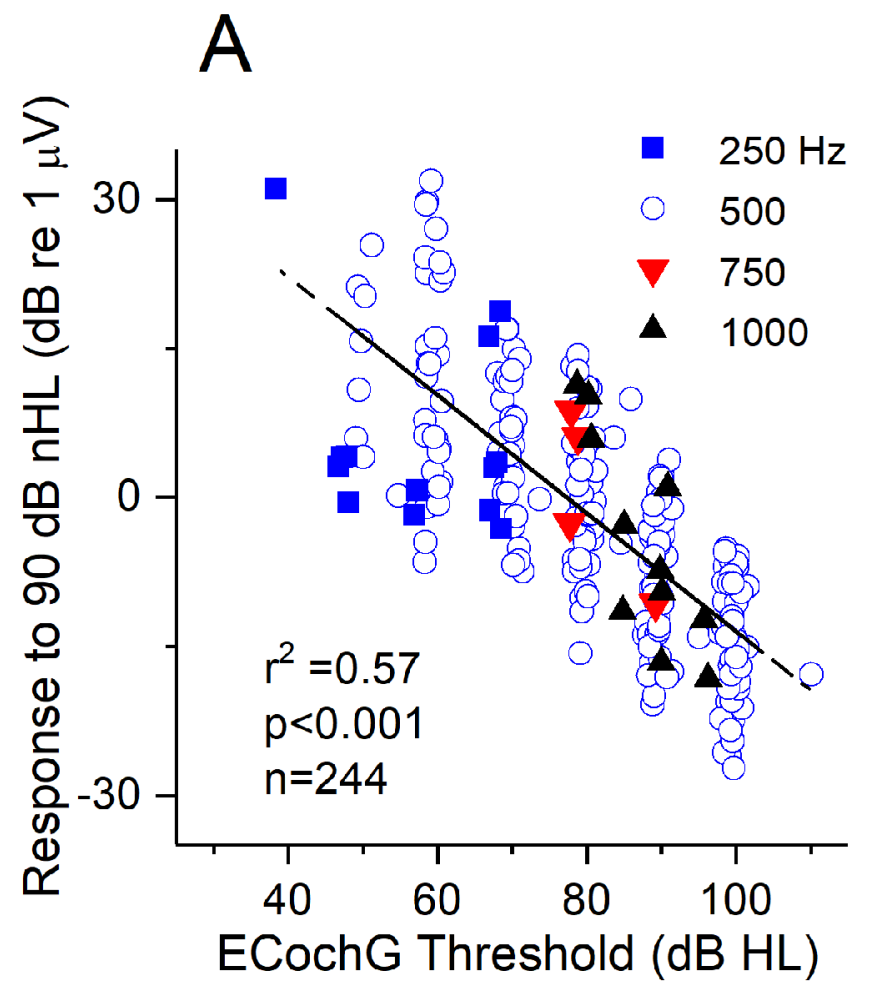

B

Figure 8.

Threshold evaluations. (A) ECochG threshold vs. magnitude. The threshold was taken at the frequency indicated by the symbol, and the response magnitude was the sum of the significant harmonics to $90 \mathrm{~dB} \mathrm{nHL}$ (corrected to HL for plotting). To look for saturation we plotted the $\mathrm{r}^{2}$ to both a linear and sigmoidal fit; since these were similar the saturation is minimal. (B). ECochG threshold vs. audiometric thresholds. These were significantly correlated, and there were many ECochG thresholds that were lower than the audiometric thresholds (above the dashed line of equality). 
Table 1.

Demographics for Adults with word scores

\begin{tabular}{|c|c|c|c|}
\hline & & \multicolumn{2}{|c|}{ Ages } \\
\hline & & $<80$ & $>=80$ \\
\hline & number of cases & 73 & 11 \\
\hline \multirow[t]{2}{*}{ Sex } & Female & 45 & 6 \\
\hline & Male & 28 & 5 \\
\hline \multirow[t]{3}{*}{ Audiology } & 3-tone threshold (dB HL) & $83.8 \pm 16.4$ & $77.6 \pm 12.8$ \\
\hline & Duration of CI use (years) & 0.5 & 0.5 \\
\hline & CNC score (\% Correct) & $55.3 \pm 20.4^{*}$ & $33.8 \pm 17.3^{* * *}$ \\
\hline Etiology of & SNHL & 53 & 9 \\
\hline \multirow[t]{11}{*}{ Hearing Loss } & Meniere's & 7 & 2 \\
\hline & barotrauma & 2 & \\
\hline & ANSD & 1 & \\
\hline & Enlarged Aqueduct & 1 & \\
\hline & Meningitis & 1 & \\
\hline & ototoxic & 1 & \\
\hline & viral & 1 & \\
\hline & stroke & 1 & \\
\hline & radiation & 1 & \\
\hline & fracture & 1 & \\
\hline & Usher's & 1 & \\
\hline \multirow[t]{6}{*}{ Device } & AB $90 \mathrm{~K}$ & 2 & \\
\hline & AB MidScalar & 2 & \\
\hline & Cochlear 512 & 9 & 1 \\
\hline & Cochlear 522 & 2 & \\
\hline & MedEl Flex or medium & 19 & 2 \\
\hline & MedEl standard & 39 & 8 \\
\hline
\end{tabular}


Table 2.

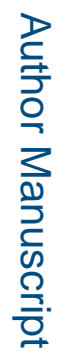

Demographics for Children with word scores

\begin{tabular}{|c|c|c|c|}
\hline & & \multicolumn{2}{|c|}{ Ages } \\
\hline & & $<1-5$ & $>5$ \\
\hline & number of cases & 63 & 31 \\
\hline \multirow[t]{2}{*}{ Sex } & Female & 35 & 17 \\
\hline & Male & 28 & 14 \\
\hline \multirow[t]{4}{*}{ Audiology } & 3-tone threshold (dB HL) & $96.4 \pm 13.7$ & $88.6 \pm 19.4$ \\
\hline & Age at CI testing & $4.4 \pm 1.4$ & $10.6 \pm 19.4$ \\
\hline & Duration of CI use (years) & $2.2 \pm 1.2$ & $1.7 \pm 1.2$ \\
\hline & PB-K score (\% Correct) & $59.7 \pm 19.7^{*}$ & $61.2 \pm 22.8^{* *}$ \\
\hline Etiology of & ANSD & 18 & 7 \\
\hline \multirow[t]{9}{*}{ Hearing Loss } & Cochlear nerve deficiency & 4 & \\
\hline & Sensorineural & 13 & 9 \\
\hline & Genetic non-syndromic & 13 & 1 \\
\hline & Genetic - syndromic & 3 & \\
\hline & Enlarged aqueduct & 5 & 9 \\
\hline & Cytomegalovirus & 2 & 4 \\
\hline & Malformation & 2 & \\
\hline & Meningitis & 2 & \\
\hline & ototoxic & 1 & 1 \\
\hline \multirow[t]{5}{*}{ Device } & AB $90 \mathrm{~K}$ & 3 & 3 \\
\hline & Cochlear 512 & 44 & 13 \\
\hline & Cochlear 422/522 & 12 & 8 \\
\hline & MedEl Flex & & 3 \\
\hline & MedEl standard & 5 & 5 \\
\hline
\end{tabular}

